\title{
REVIEW
}

\section{Bacterial bloodstream infections in the allogeneic hematopoietic cell transplant patient: new considerations} for a persistent nemesis

\author{
CE Dandoy ${ }^{1}$, MI Ardura², GA Papanicolaou ${ }^{3}$ and JJ Auletta ${ }^{2,4}$
}

Bacterial bloodstream infections (BSI) cause significant transplant-related morbidity and mortality following allogeneic hematopoietic cell transplantation (allo-HCT). This manuscript reviews the risk factors for and the bacterial pathogens causing BSIs in allo-HCT recipients in the contemporary transplant period. In addition, it offers insight into emerging resistant pathogens and reviews clinical management considerations to treat and strategies to prevent BSIs in allo-HCT patients.

Bone Marrow Transplantation (2017) 52, 1091-1106; doi:10.1038/bmt.2017.14; published online 27 March 2017

\section{INTRODUCTION}

Allogeneic hematopoietic cell transplantation (allo-HCT) is the definitive therapy for many malignancies, marrow failure syndromes and immune deficiencies in children, adolescents and adults. ${ }^{1,2}$ Transplant strategies and supportive care have evolved over the past few decades, resulting in improved overall survival (OS). ${ }^{3}$ Despite these advances, infection remains a primary cause of death following allo-HCT. Allo-HCT patients are at increased risk of developing bacterial bloodstream infections (BSIs), which are among the most serious infectious complications, leading to prolonged hospitalization and exposure to antimicrobial therapy, increasing nosocomial infection risk. In addition, BSI often results in the need for intensive care and increases non-relapse mortality (NRM). ${ }^{4-6}$ Central line-associated bloodstream infections (CLABSIs) are serious complications in HCT recipients and lead to prolonged hospitalization, and intensive care admissions. ${ }^{4-7}$ According to National Healthcare Safety Network (NHSN) data, CLABSI incidence continues to be highest in the HCT population, wherein rates are higher than in any other high-risk population, including solid organ transplant and burn patients, or care setting (that is, intensive care units). ${ }^{8}$ This paper will review the impact of bacterial BSI in the current transplant period as measured by resource utilization and associated morbidity and mortality in allo-HCT patients. The manuscript will also offer insight into emerging resistant pathogens responsible for causing bacterial BSI and novel antimicrobial therapies and approaches implemented to reduce BSI-related morbidity and mortality in allo-HCT patients.

\section{DEFINITIONS}

An important challenge in interpreting data is ensuring accurate definitions. BSIs in the healthcare setting are classified as either primary $\mathrm{BSI}$, related to either a central venous catheter (CVC) or other hospital-acquired source, or secondary BSI, a bacteremia related to another site of infection (for example, abscess or pneumonia). ${ }^{9}$ Thus, unless an alternative source is identified, all BSIs in patients with a CVC are considered CLABSIs. Some patients with CVCs experience BSIs that do not arise from the catheter, but rather originate from translocation of bacteria through non-intact oral and gut mucosa. ${ }^{9,10}$ To address this type of BSI, the Centers for Disease Control and Prevention defined a specific CLABSI type known as 'mucosal barrier injury laboratory-confirmed bloodstream infection' (MBI-LCBI) based on literature review and expert opinion. In 2013, the MBI-LCBI definition was integrated into NHSN methods for primary BSI surveillance to identify a subset of BSIs reported as CLABSIs that were likely related to mucosal barrier injury in the mouth and gut and not the presence of the CVC itself. $^{9}$ (Figure 1) Currently, the NHSN defines primary BSIs in patients with a CVC as 'laboratory-confirmed bloodstream infection (LCBI)' and subcategorized as 'CLABSI' or 'MBI-LCBI'. ${ }^{11}$ Inherent to this distinction is emerging evidence showing that improved CVC maintenance is effective at reducing CLABSI rates, ${ }^{12-14}$ but not in preventing MBI-LCBIs. ${ }^{15}$

CLABSI and MBI-LCBI are terms utilized by the NHSN for BSI surveillance. To augment this the Infectious Disease Society of America (IDSA) produced guidelines for the detection of bacteremia in patients with CVCs utilizing the term 'catheterrelated bloodstream infection' (CRBSI). ${ }^{16}$ CRBSI is a clinical definition used to determine if the presence of bacteremia originates from the CVC, or from another source. Confirming a CRBSI diagnosis includes calculating the differential time-topositivity between equal volume blood cultures drawn concomitantly from the CVC and a peripheral site or a second CVC lumen. ${ }^{16}$ In pediatric oncology patients, blood cultures drawn from the central CVC site that grow $\geqslant 150 \mathrm{~min}$ before blood cultures from a peripheral site predict that the CLABSI is from a colonized CVC with $89 \%$ sensitivity and $100 \%$ specificity. ${ }^{16,17}$ If peripheral blood cultures are not obtained, but blood cultures are obtained from both lumens of a double lumen CVC,

\footnotetext{
${ }^{1}$ Bone Marrow Transplantation and Immune Deficiency, Cincinnati Children's Medical Center, Cincinnati, OH, USA; ${ }^{2}$ Host Defense Program, Infectious Diseases, Nationwide Children's Hospital, Department of Pediatrics, The Ohio State University College of Medicine, Columbus, OH, USA; ${ }^{3}$ Infectious Disease Service, Memorial Sloan Kettering Cancer Center, New York, NY, USA and ${ }^{4}$ Hematology/Oncology/BMT, Nationwide Children's Hospital, Columbus, OH, USA. Correspondence: Dr CE Dandoy, Bone Marrow Transplantation and Immune Deficiency, Cincinnati Children's Hospital Medical Center, 3333 Burnet Avenue, MLC 11027, Cincinnati, OH 45229-3039, USA.
}

E-mail: christopher.dandoy@cchmc.org

Received 23 September 2016; revised 20 December 2016; accepted 12 January 2017; published online 27 March 2017 


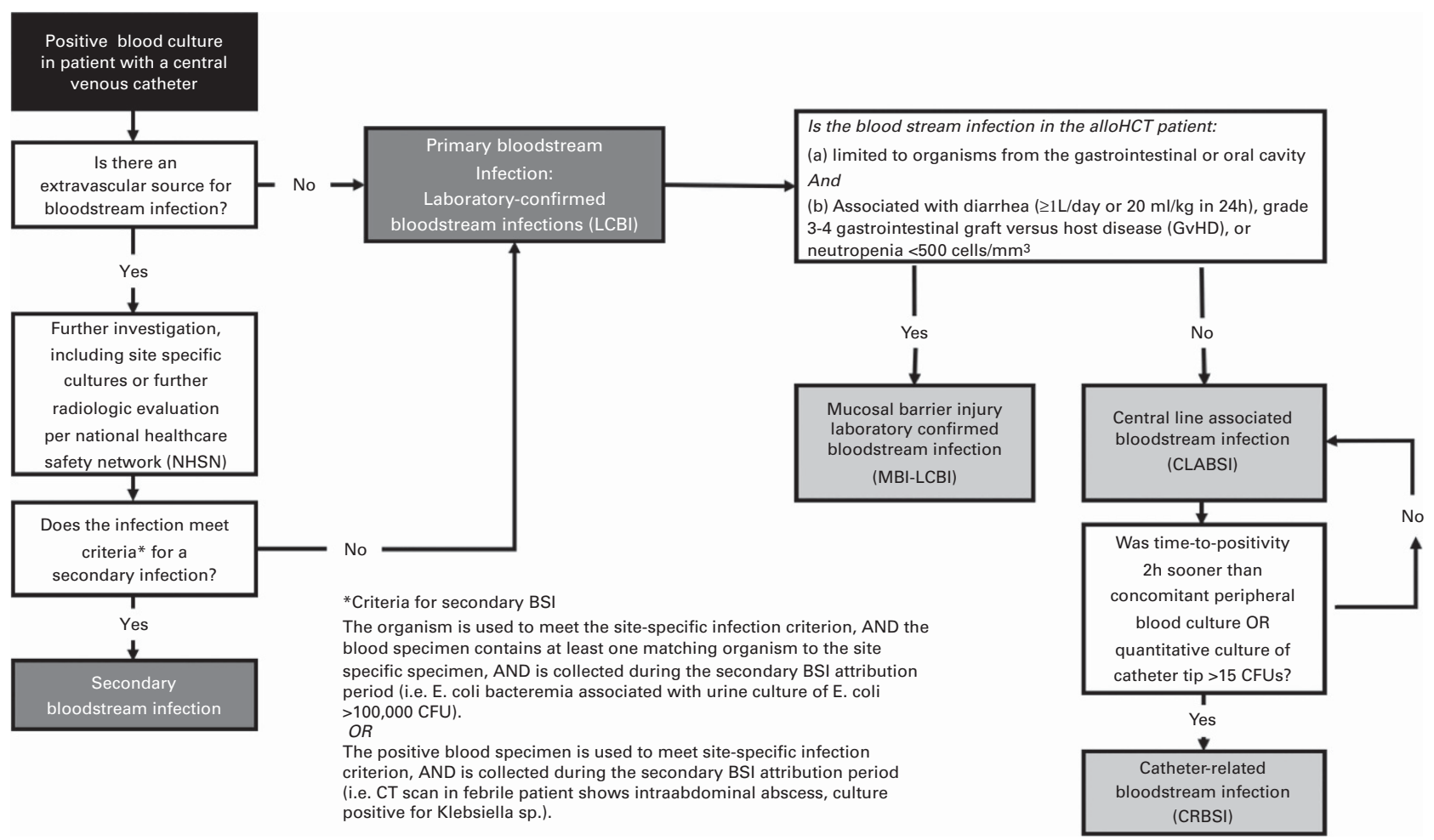

Figure 1. Classification of primary and secondary bloodstream infections (BSI) per 2016 National Healthcare Safety Network (NHSN). Primary BSIs are caused by a common commensal organism, isolated from a blood culture on two occasions, or a recognized pathogen isolated from one blood culture. Specific criteria must be met for secondary BSI or mucosal barrier injury laboratory-confirmed bloodstream infection (MBI-LCBI) designations. Otherwise, BSIs are classified as a central line-associated bloodstream infection (CLABSI).

a differential time-to-positivity of $\geqslant 180 \mathrm{~min}$ can be used to diagnose a CLABSI with $61 \%$ sensitivity and $94 \%$ specificity. However, this comparison has a poor negative predictive value. ${ }^{18}$

\section{EPIDEMIOLOGY}

The incidence of BSI and associated bacteria types vary widely by geographic location, patient population, and study design. BSI is the most common infectious complication following adult (Table 1) and pediatric (Table 2) allo-HCT.

Mikulska et al. ${ }^{19}$ showed $60 \%$ of all BSIs occurred in the pre-engraftment period. Kikuchi et al. ${ }^{20}$ showed similar results in their retrospective review, noting that BSIs were more common in the pre- (39\% of patients) vs post-engraftment ( $17 \%$ of patients) periods. During the pre-engraftment period, important risk factors for $\mathrm{BSI}$ are neutropenia, presence of a CVC and severe mucositis. ${ }^{21}$ In multivariate analysis, pre-engraftment BSI has been associated with engraftment failure and high-risk disease status at the time of $\mathrm{HCT}^{20}$

Post-engraftment BSIs are more commonly found in patients who undergo allo-HCT and have a history of acute (aGvHD) or chronic GvHD (cGvHD). Patients with post-engraftment BSI received more antibacterial prophylaxis, previous antibiotic therapy and immunosuppression (corticosteroids and cyclosporine) than patients without BSI. ${ }^{20,21}$ In addition, patients with postengraftment BSIs traditionally have poorer outcomes, with higher early and all-cause fatality rates. ${ }^{21}$

\section{RISK FACTORS}

Risk factors for BSI include age greater than 18 years, use of unrelated graft source and myeloablative conditioning regimen, acute GvHD, mucositis, transplant-associated thrombotic microangiopathy (TA-TMA), high-risk malignant disease and steroid use ${ }^{5,22}$ (Figure 2).

\section{Graft source}

Ballen et al. ${ }^{23}$ compared the incidence of bacterial, viral and fungal infections in 1781 adults with acute leukemia who received alternative donor HCT between 2008 and 2011. Over 50\% of patients developed bacterial infections by 1 year post HCT. In multivariable analysis, bacterial infections were more common after mismatched unrelated donor (MMUD) than matched unrelated donor (MUD) grafts $(P=0.0295)$ and most common after umbilical cord blood (UCB) vs MUD $(P<0.001)$ or MMUD grafts $(P=0.0009)$, likely due to the slower engraftment and delayed immune recovery associated with UCB. ${ }^{23}$ Although UCB are associated with increased BSI rates, Sanz et al. ${ }^{24}$ reported that higher $\mathrm{CD}^{+}$cell doses in UCB grafts independently associated with reduced risk of BSI.

Young et al. $^{25}$ conducted a phase three, multicenter, randomized trial comparing HCT outcomes using unrelated bone marrow (BM) and peripheral blood (PB). Although 2-year OS was similar between the two graft sources, BSIs at 100 days and two years post HCT were higher in patients receiving BM grafts. The cumulative incidence of BSI during the first 100 days was $44.8 \%$ (95\% confidence interval $(\mathrm{Cl}), 38.5-51.1)$ for $\mathrm{BM}$ vs $35.0 \%$ (95\% Cl, 28.9-41.1) for PB ( $P=0.027)$; and the two-year cumulative incidence of BSI was $72.1 \%$ and $62.9 \%$ in BM vs PB recipients, respectively $(P=0.003){ }^{25}$

Haploidentical HCT is emerging as a comparable alternative to MUD transplantation with respect to disease control and complications. Despite a notable increase risk for viral-related morbidity and mortality, haploidentical HCT currently does not appear to be associated with increased BSI risk. ${ }^{26}$ 


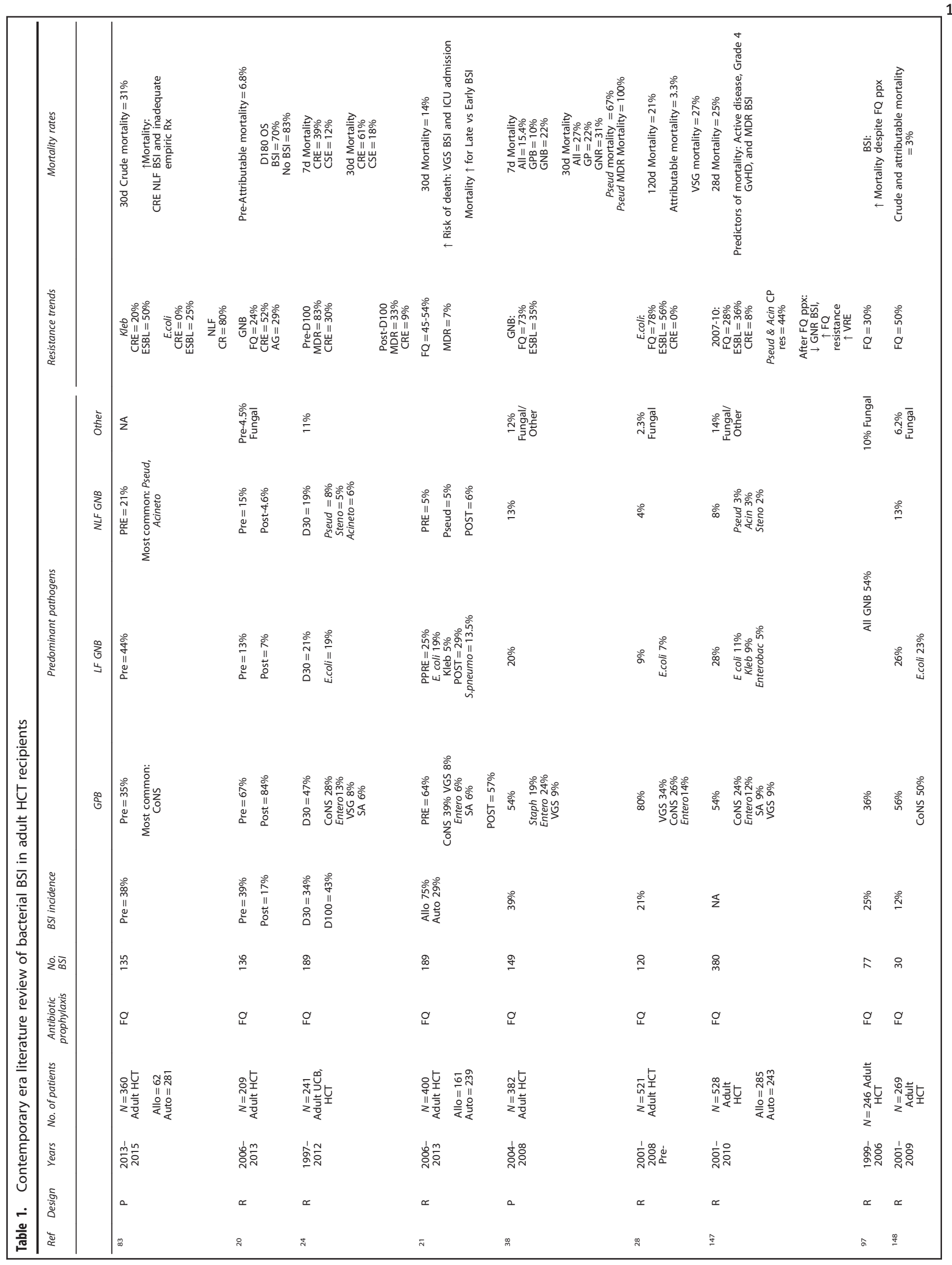




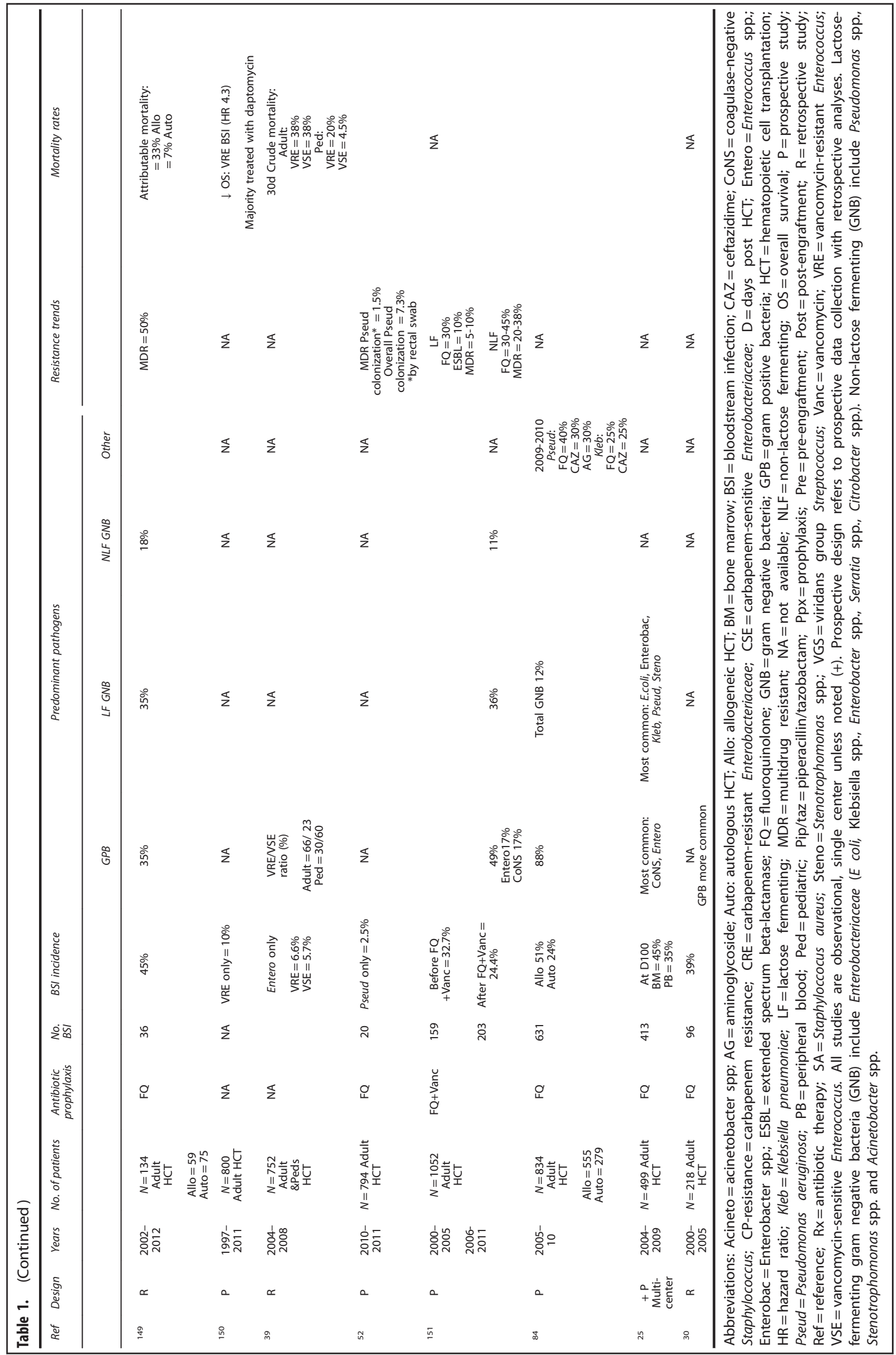




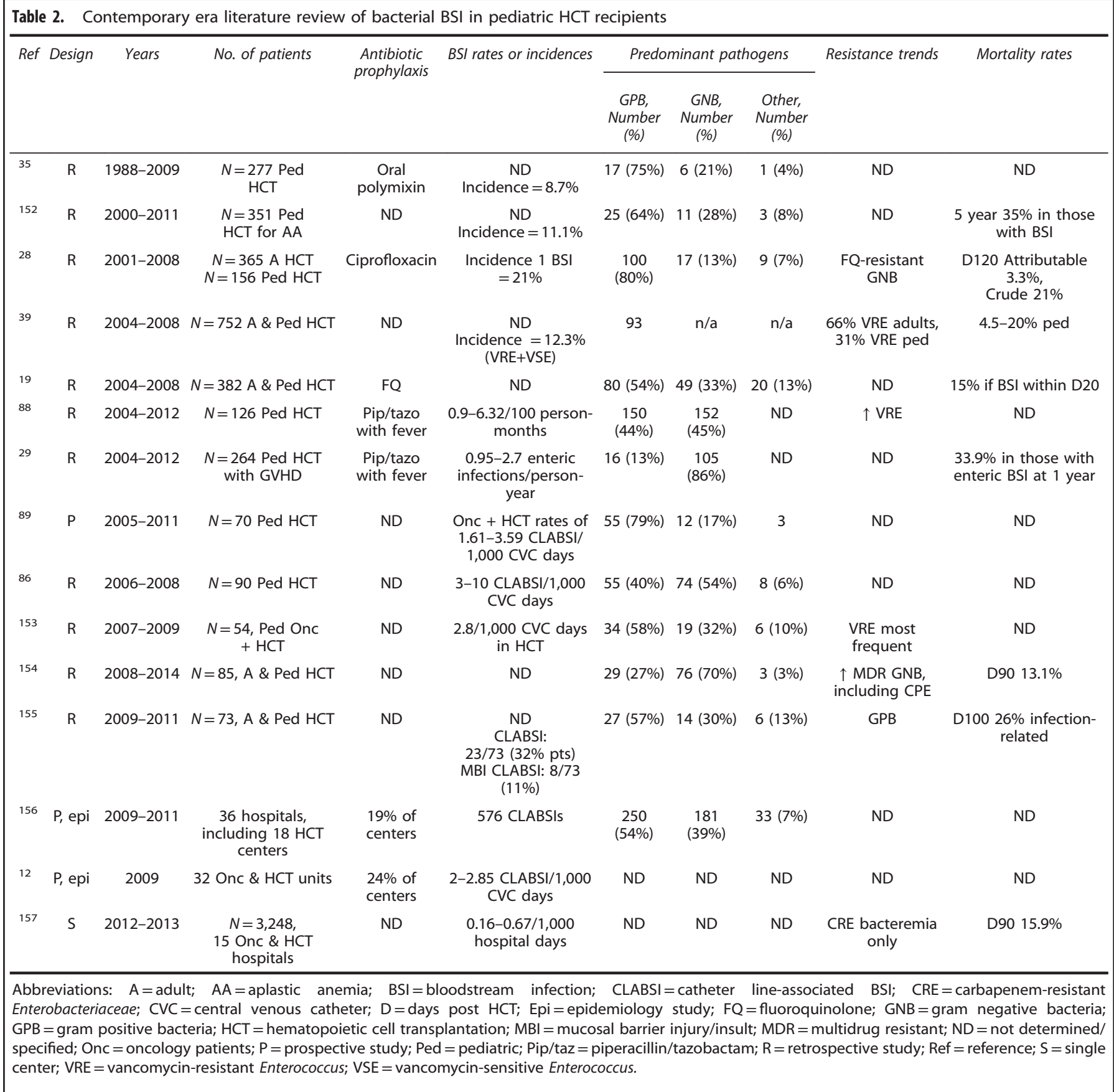

\section{Conditioning regimen}

Reduced-intensity conditioning (RIC) is associated with less regimen-related toxicity than myeloablative conditioning (MAC) regimens. ${ }^{27}$ As such, patients receiving $\mathrm{RIC}$ conditioning regimens typically have lower rates of BSI, likely due to decreased mucositis and shorter durations of neutropenia. ${ }^{27,28}$ However, pediatric patients undergoing RIC transplant for non-malignant disease have been noted to have an increased BSI risk, ${ }^{5}$ which may reflect the added risk for BSI associated with the underlying diagnosis itself (for example, primary immunodeficiency).

\section{Acute GvHD}

Damage to the gastrointestinal epithelium caused by aGvHD may facilitate bacterial translocation across the gastrointestinal mucosal barrier. BSI rates secondary to enteric bacteria in the first 120 days following allo-HCT are three times higher following rather than preceding aGvHD. ${ }^{29}$ Also contributing to increased BSI risk following aGvHD is its associated intensive immunosuppressive therapy. ${ }^{30}$ In murine allo-HCT models, aGvHD causes a shift toward predominance of gram negative organisms, which, in turn, increases the risk for sepsis-related morbidity and mortality. ${ }^{31}$ In addition, Paneth cells which selectively kill noncommensals through secretion of a-defensins are targeted by aGvHD. ${ }^{32,33}$

Transplant-associated thrombotic microangiopathy

TA-TMA causes generalized endothelial dysfunction that can progress to multi-organ injury and poor transplant outcome. ${ }^{34}$ 
Risk factors for bacterial bloodstream infection in hematopoietic cell transplantation patients

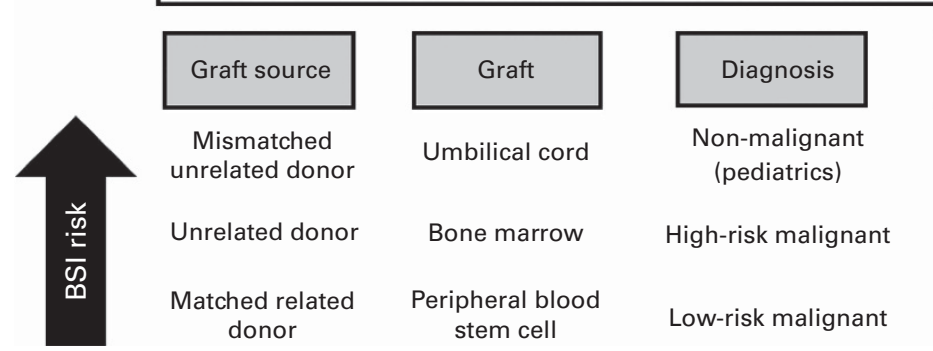

Figure 2. Risk factors for bacterial bloodstream infection (BSI) in hematopoietic cell transplant patients. Risk factors for bloodstream infections within each listed patient- and transplant-related demographic are listed from lowest to highest bloodstream infection risk.

TA-TMA is frequent after HCT, occurring in about one-third of patients if monitored carefully and leads to systemic vascular injury and widespread tissue injury. The intestine can also be a target of TA-MA, potentially leading to bacterial translocation and interestingly, TA-TMA is strongly associated with MBI-LCBI. ${ }^{5}$ Patients with TA-TMA might benefit from preventative strategies to reduce $\mathrm{MBI}-\mathrm{LCBI}$.

\section{Other risk factors}

High-risk malignant disease such as acute myelogenous leukemia not in remission at the time of HCT is associated with increased risk of post-HCT $\mathrm{BSI}^{20}$ In pediatric populations, non-malignant diseases are associated with higher BSI risk than malignant diseases. ${ }^{5,35}$

\section{EMERGING RESISTANCE IN BLOODSTREAM INFECTION PATHOGENS IN THE CONTEMPORARY TRANSPLANT PERIOD}

Few studies address etiology and resistance patterns for bacterial pathogens responsible for BSI in HCT recipients. Although several single-center, retrospective analyses have been published in the last 10 years, many refer to data obtained prior to the current contemporary transplant period (2010-2015). As the etiology of infections in these reporting hospitals may have changed, reflecting different infection prevention and management strategies, many of the published resistance rates in these studies are likely obsolete. General trends in contemporary studies include an overall decreased incidence of BSI compared to earlier studies. ${ }^{22,36,37}$ While the overall incidence of BSI by gram negative bacteria has decreased, the proportion of BSI caused by fluoroquinolone-resistant bacteria has increased compared with prior studies (Table 1). Similarly, contemporary microbial epidemiology data in pediatric HCT over the last 5 years demonstrates a decrease in CLABSI rates with a suggestive trend toward less predominance of gram positive bacteria and selection of multidrug resistant (MDR) pathogens (Table 2).

Center-specific infection control and antibiotic stewardship practices are seldom reported in published studies, but likely contribute to observed BSI heterogeneity across centers. In 2014, Mikulska et al. ${ }^{38}$ distributed a questionnaire to assess bacterial resistance and empiric antibiotic use to institutions across 18 countries. Thirty-nine ${ }^{39}$ centers completed and evaluated changes in pathogen resistance patterns over 5 years (2005-2011). The individual centers reported reduction in gram positive to gram negative bacteria ratios (55:45 vs 60:40\%), increased rates in Enterococcus spp. (8 vs 5\%) and Enterobacteriaceae spp. (30 vs $24 \%$ ), and decreased rates in Pseudomonas aeruginosa (5 vs 10\%) from earlier to more recent time periods. However, rates of extended spectrum beta-lactamase (ESBL)-producing organisms, aminoglycosideresistant gram negative bacteria and carbapenem-resistant $P$. aeruginosa were substantially increased, ${ }^{38}$ reflecting emergence of these resistant pathogens.

\section{Vancomycin-resistant Enterococcus}

BSI with vancomycin-resistant Enterococcus (VRE) is emerging in pediatric and adult $\mathrm{HCT}$ recipients. ${ }^{39}$ In a single-center report, the rate of VRE was substantially higher for adult patients than pediatric patients; and VRE BSI resulted in inferior one-year OS post-HCT. ${ }^{39}$ In addition, patients with VRE BSI have significantly longer duration of (attributable difference 2.1 days longer) and costs in hospitalization. ${ }^{40}$

Enterococcus faecium has emerged as a leading cause of MDR enterococcal infection in the United States; ${ }^{41}$ as VRE is responsible for nearly $18 \%$ of all invasive enterococcal infections in North America, with an incidence nearly doubling in recent years. ${ }^{41}$ Importantly, $E$ faecium is intrinsically more antibioticresistant than $E$ faecalis with more than half of its pathogenic isolates expressing resistance to vancomycin and ampicillin. As a result, treating infections caused by this species can be difficult. ${ }^{42}$ The primary mode of spread of VRE from patient-topatient occurs through the hands of healthcare workers. Enterococci can persist for as long as $60 \mathrm{~min}$ after inoculation onto hands and up to 4 months on inanimate surfaces, where they can serve as a reservoir for ongoing transmission in the absence of regular decontamination. ${ }^{43,44}$

Antibiotic therapy leading to VRE gastrointestinal overgrowth may lead to a unique pathogenesis and predisposition to gut translocation and bacteremia. ${ }^{45,46}$ Specifically, perturbation of normal commensal intestinal microbiota by antibiotics and domination by VRE were shown to precede VRE BSI in allo-HCT patients. ${ }^{46}$

\section{Methicillin-resistant Staphylococcus aureus}

Methicillin-resistant Staphylococcus aureus (MRSA) produces virulent biofilms on invasive, foreign devices like endotracheal tubes and endovascular catheters. ${ }^{4,48}$ Biofilm facilitates MRSA survival and multiplication, prolonging the organism's exposure to antibiotics as well as promoting the transfer of antibiotic resistance genes among strains. ${ }^{49}$ Use of antibiotics, particularly cephalosporins and fluoroquinolones, strongly correlates with MRSA colonization and infection. In 2007, Shaw et al. evaluated the frequency and outcome of patients who developed MRSA BSI over a 5-year period. The frequency of MRSA infections in autologous, MSD and MUD transplants was 3, 6 and $9 \%$, respectively and in $7 \%$ of the infections MRSA was directly implicated in patient mortality. ${ }^{50}$ 
MDR gram negative bacteria

MDR bacterial strains are defined by their resistance to three or more antibiotic classes: carbapenems (imipenem, meropenem); penicillins (piperacillin, ticarcillin and piperacillin-tazobactam); cephalosporins (ceftazidime, cefepime); monobactams; aminoglycosides and fluoroquinolones. In the aforementioned 2014 European survey, median reported rates of ESBL-producing gram negative bacteria (15-24\%), aminoglycoside-resistant gram negative bacteria (5-14\%) and carbapenem-resistant $P$. aeruginosa (5-14\%) were substantial. ${ }^{38}$ Consistent with the European survey, a recent study reported a $17.5 \%$ ESBL gram negative colonization rate among HCT patients in Germany with only $2 \%$ of colonized patients developing bacteremia. $^{51}$ In a 2015 report from MD Anderson Cancer Center, ${ }^{52}$ rates of stool colonization with MDR Pseudomonas were $1.2 \%(12 / 794)$; however, seven $(58 \%, 7 / 12)$ of the colonized patients went on to develop MDR Pseudomonas BSI. Differences in geography, infection control and antibiotic stewardship likely contribute to the variable rates of infection by these resistant pathogens.

\section{Carbapenem-resistant Enterobacteriaceae (CRE) and Klebsiella (CRK)}

Previously, Enterobacteriaceae were reliably susceptible to carbapenems despite resistance to other antimicrobial classes. Unfortunately, carbapenem-resistant Enterobacteriaceae (CRE) are now reported globally. In the US, CRE infections are almost exclusively caused by K. pneumoniae carbapenemase production. Importantly, CRE infections in HCT patient are rapidly lethal and have very limited therapeutic options. Satlin et al. reported that CRE caused $2.2 \%$ of all BSIs and $4.7 \%$ of BSI by gram negative bacteria in neutropenic patients with hematologic malignancies in two institutions. ${ }^{53}$ Multiple antibiotics, steroids and prior CRE colonization were determined to be risk factors for CRE BSI, and delay in receipt of CRE-active therapy was associated with worse outcomes. First described in India, New Delhi metallo- $\beta$-lactamase1 (NDM-1)-producing CRE have since spread globally. NDM-1 confers resistance to all available $\beta$-lactams except aztreonam and is associated with mortality rates exceeding $50 \%$. In a recent study from MD Anderson, the rate of CRE in BSI isolates was 2.5\% among adult oncology patients, with $55 \%$ carrying the NDM-1 gene in a non-outbreak setting. ${ }^{54}$ All these isolates were resistant to ceftazidime-avibactam. ${ }^{54}$

Carbapenem-resistant Klebsiella pneumoniae (CRK) has recently been described in the HCT population. Germenia et al. determined the epidemiology and outcomes of HCT recipeints who develop a CPK BSI. ${ }^{55}$ CPK infections were diagnosed in $0.4 \%$ of autologous $\mathrm{HCT}$ recipients and $2 \%$ of allo-HCT recipients at a median of $8( \pm 11.6)$ and $15( \pm 83.6)$ days post transplant, respectively. In addition, CRK infection increased over sevenfold from 2010 to 2013 in allo-HCT patients (0.4-2.9\%). CRK colonization documented before or after transplant was followed by an infection in 39\% of allo-SCT patients, which was associated with a $64 \%$ infection-related mortality. ${ }^{55}$

\section{MICROBIOLOGICAL DETECTION OF BLOODSTREAM INFECTIONS IN HCT PATIENTS}

Bloodstream infection detection

The Infectious Disease Society of America produced guidelines for the detection of bacteremia in patients with a CVC. ${ }^{16}$ These recommendations include the timing and volume of blood culture collection. New modalities such as matrix-assisted laser desorption/ionization time-of-flight mass spectrometry and multiplex molecular blood culture diagnostics may allow for more rapid identification of certain BSI pathogens in clinical specimens, thus improving time to effective and optimal antimicrobial therapy. ${ }^{56}$ Whether application of these diagnostic methods has a measurable impact on HCT patient outcomes remains to be elucidated. ${ }^{57}$

Role of surveillance blood cultures

A retrospective study of asymptomatic adult allo-HCT recipients with CVCs who had 6801 surveillance blood cultures performed showed surveillance cultures infrequently yielded significant results $(0.59 \%$ of all surveillance blood cultures drawn) and were associated with unnecessary medical interventions and added cost. $^{58} \mathrm{~A}$ prospective observational study in allo-HCT recipients receiving steroids who underwent daily blood culture surveillance also did not demonstrate a clear benefit and rarely identified a CLABSI. ${ }^{59}$ Similarly, small case series of weekly BSI surveillance in asymptomatic children undergoing HCT demonstrated very low yield and significant cost, with no clear improvement in patient outcomes and higher rates of detection of contaminants. ${ }^{60,61}$ Taken together, the published literature do not support the utility of surveillance blood cultures in HCT.

Screening for resistant bacteria

Transformation of non-resistant to MDR organisms in HCT patients occurs through antibiotic selection, patient-to-patient transmission and de novo development of antibiotic resistance. ${ }^{62,63}$ Active surveillance may reduce transmission of MDR organisms when performed in high-risk patient care units. ${ }^{64}$ Surveillance cultures for MRSA, VRE and other MDR gram negative bacteria can be obtained from skin, nasal and rectal swabs, or stool samples.

Although research on the prevalence and prevention of MRSA exists in other vulnerable populations, data on MRSA carriage, screening and associated morbidity and mortality in the HCT population is limited. National HCT guidelines do not offer recommendations for routine screening for MRSA carriage, as no studies have demonstrated associations between pre-transplant carriage and post-transplant infections. A retrospective study conducted at a large comprehensive cancer center demonstrated that the prevalence of pre-transplant MRSA nasal carriage detected by culture was low in HCT recipients. ${ }^{65}$ Furthermore, no patients with proven pre-transplant nasal carriage developed post-transplant MRSA complications. Interestingly, only a minority of $S$. aureus acquisitions can be explained by patient-to-patient transmission. ${ }^{66}$

Patients with known VRE colonization have a higher risk of developing VRE BSI than patients without VRE. ${ }^{67}$ However, VRE surveillance has not conclusively demonstrated reduction in VRE bacteremia in HCT recipients. Surveillance for MDR organisms (including CRE and MDR Pseudomonas spp. and intrinsically resistant organisms like Acinetobacter spp.) should be considered on a case-by-case basis for patients who come from areas with high endemicity, in an outbreak setting and in patients who have had previous infections with MDR pathogens. ${ }^{68}$

\section{MANAGEMENT OF BLOODSTREAM INFECTIONS}

Antimicrobial therapy

Pathogen-directed antibiotic therapy should be determined by identifying the causative organism and defining its associated susceptibility patterns. Once a pathogen is isolated by blood culture, repeat cultures are recommended until clearance of BSI is achieved. Duration of antimicrobial therapy varies by site of infection, pathogen and extent of neutropenia. Uncomplicated MBI-LCBIs require 7-14 days of antibiotic therapy from the date of first sterile blood culture or resolution of neutropenia, whichever is longer. Similarly, in the absence of an endovascular or metastatic foci of infection, uncomplicated CRBSI, duration of antimicrobial therapy is generally 7-14 days (depending on pathogen) from the date of catheter removal, blood culture sterilization and resolution 
of neutropenia. ${ }^{16}$ For common skin contaminants, a shorter duration (5-7 days) may be considered for patients who are clinically stable. Patients with complicated CLABSI, including those with persistent bacteremia despite $\geqslant 72 \mathrm{~h}$ of effective antibiotic therapy or after catheter removal, may require prolonged treatment of up to 4-6 weeks given concern for an endovascular source for persistent infection.

\section{Antimicrobial therapy for resistant pathogens-VRE}

Four drugs active against VRE have been licensed for use: quinupristin-dalfopristin, linezolid, tigecycline and daptomycin. Linezolid has been used as treatment for VRE in the cancer and transplant settings. Specifically, empiric use of linezolid in VRE-colonized hematology patients did not impact infectionrelated mortality (IRM), which appears to be associated with persistence of neutropenia vs in HCT patients, in whom IRM was associated with GvHD. ${ }^{69}$ In the HCT population, VRE colonization prior to allo-HCT was a risk factor for increased day 100 mortality, which appeared to be related to development of subsequent VRE bacteremia, and persisted after adjusting for baseline variables. ${ }^{39}$

Daptomycin is also used for treatment of VRE BSI, particularly in patients where there is concern for linezolid-induced hematologic toxicity. In 2009 surveillance studies from US hospitals demonstrated that more than $99.5 \%$ of VRE isolates were susceptible to daptomycin. However, subsequent emergence of daptomycinresistant VRE during therapy has been described, particularly in adult oncology patients. At Memorial Sloan Kettering, daptomycin-resistant VRE bacteremia increased from $3.4 \%$ in 2007 to $15.2 \%$ in $2009 .^{70}$ Furthermore, daptomycin minimal inhibitory concentrations of $3-4 \mu \mathrm{g} / \mathrm{mL}$ in the initial $E$ faecium blood isolate predicted microbiological failure of daptomycin therapy, suggesting that the recommended daptomycin dose is suboptimal for treating VRE bacteremia and modification in the daptomycin breakpoint for Enterococci may need to be considered. ${ }^{71,72}$ Despite high treatment failures of up to $60 \%$ and meta-analyses comparing linezolid to daptomycin, the optimal treatment for VRE BSI has not been established. ${ }^{73}$ These data suggest that without susceptibility data, empiric daptomycin therapy for VRE infections should be used with caution, particularly in patients who have received prolonged therapy with vancomycin.

Antimicrobial therapy for MDR pathogens-carbapenem-resistant Enterobacteriaceae and Klebsiella

Widespread use of carbapenems has contributed to the development of carbapenem-resistant bacteria, with an increasing number of MDR gram negative isolates being reported to the NHSN. ${ }^{74}$ Critically ill HCT patients with a prior history of infection or colonization with MDR CRE require tailored empirical antimicrobial regimen at the time of initial fever and blood culture acquisition. Despite limited effective antibiotic options, targeted antimicrobial therapy for proven MDR CRE infections should include at least two active agents. Antimicrobial therapies used for MDR CRE include polymyxin, colistin, aminoglycosides (if susceptible), tigecycline, high-dose continuous carbapenem infusions, ceftolozane/tazobactam and ceftazidime/avibactam. ${ }^{75}$ Ceftolozane/tazobactam and ceftazidime/avibactam are novel $\beta$-lactam/ $\beta$-lactamase combination antibiotics, whose antimicrobial spectrum of activity includes MDR gram negative bacteria, including $P$. aeruginosa. Ceftazidime/avibactam also has activity against $K$. pneumoniae carbapenemases. Clinical trials demonstrated efficacy of both agents when used in the treatment of complicated urinary tract infections and complicated intraabdominal infections when used with metronidazole. However, neither agent is currently indicated for the treatment of BSI CRE; and no clinical trials have been published using these two agents for MDR CRE infections in immunocompromised patients. ${ }^{76}$ In patients with CRK, combination therapy with colistin/polymyxin $B$, tigecycline and gentamicin with the addition of meropenem is recommended. ${ }^{68}$ In summary, keys to successful management of MDR pathogens are correct identification of bacteria, early initiation of effective therapy and stringent infection control measures to prevent transmission to other patients. ${ }^{68}$

\section{Antimicrobial lock therapy}

Intraluminal colonization and biofilm formation allow pathogens to evade immune clearance and attenuate antimicrobial efficacy. Antibiotic locks provide a small, but high concentration of an antimicrobial agent active against the CLABSI pathogen that dwells for an extended time in the CVC lumen in an attempt to eradicate both the pathogen and its associated biofilm, thus enabling catheter salvage. The addition of an antibiotic lock to concomitant intravenous antimicrobial therapy is recommended by current IDSA guidelines for uncomplicated CLABSI when catheter salvage is indicated and attempted. ${ }^{16}$ However, in a retrospective, case-matched cohort study of CLABSI in pediatric oncology patients, one-third of whom were $\mathrm{HCT}$ recipients, no evidence of additional benefit from adjunctive antibiotic lock therapy was demonstrated. ${ }^{77}$ In addition, vancomycin locks have been found to increase risk for selecting gram positive bacteria with reduced susceptibility to vancomycin. ${ }^{78}$

Ethanol locks are attractive options for adjunctive therapy for CLABSI given that ethanol readily penetrates biofilm, has thrombolytic and anticoagulant properties, and has activity against both bacteria and fungi without promoting emergence of antimicrobial resistance. However, ethanol locks are generally restricted to patients with silicone-based CVCs based upon concerns for possible mechanical complications when used in polyurethane catheters. Efficacy of ethanol locks has been demonstrated mostly in other populations requiring CVCs (for example, short bowel syndrome patients), as published data on ethanol locks in the HCT population is limited. One small, randomized, prospective trial in adult hematology patients with tunneled CVCs did not show differences in CLABSI rates, comparing heparinized saline with $70 \%$ ethanol locks with $2 \mathrm{~h}$ dwell times. ${ }^{79}$ Review of published data of ethanol locks for both prevention and adjunctive treatment of CLABSI in children demonstrated improvement in CLABSI rates after implementation, but also reported some adverse events in pediatric oncology patients. ${ }^{80}$ Additional data are required to assess the efficacy of ethanol locks for standard therapy and prevention of CLABSIs in $\mathrm{HCT}$ patients prior to making recommendations regarding its use in these patients.

\section{When to remove/replace a central line}

Current guidelines recommend CVC removal when there is an implantable port pocket or tunnel infection and for CLABSI caused by S. aureus, Pseudomonas aeruginosa, Stenotrophomonas maltophilia, MDR bacteria, VRE, Candida spp. and atypical mycobacteria. ${ }^{16,81}$ In addition, catheter removal is advised when there is evidence of complicated CLABSI (for example, thrombophlebitis, endocarditis, severe sepsis) and continued BSI despite $\geqslant 72 \mathrm{~h}$ of effective antibiotic therapy. For uncomplicated CLABSI involving less virulent pathogens like Bacillus, Micrococcus or Propionibacterium spp., catheters should be removed if CLABSI is proven based on $\geqslant$ two blood cultures revealing the same organism. In the aforementioned clinical settings, catheter removal has been associated with reduced infection relapse and metastatic complications. However, in patients who require ongoing, long-term CVC access, catheter removal may not always be feasible and catheter salvage may be required. (Figure 3 ). 


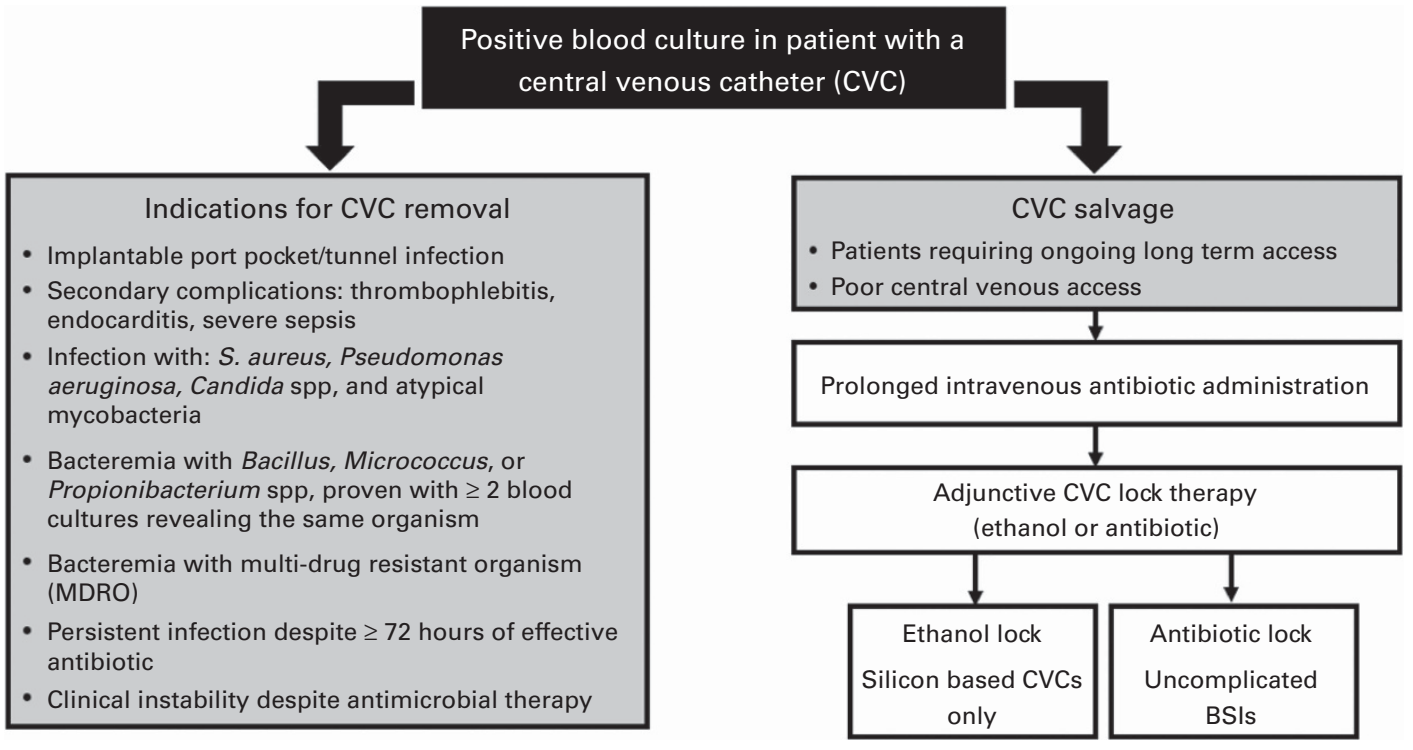

Figure 3. Disposition of the central venous catheter (CVC) following bloodstream infection. Indications for CVC removal and retention and potential use of lock therapy are listed.

Table 3. Recommendations for prevention of central venous cather (CVC)-related infection in HCT recipients

Education, Training and Staffing Regular education should be provided for all staff caring for and placing CVCs

- Regular assessment of provider knowledge and adherence to guidelines is advised

- Designate only trained personnel who demonstrate competence for placement and maintenance of CVCs

- Ensure appropriate nursing staff levels

Catheter type, insertion site and placement CVCs should be placed by well-trained personnel

- Selection of CVC should be determined by the duration of use and ability of the patient to provide care

- The minimum number of lumens required for patient management is recommended

- CVC insertion in the femoral vein should be avoided, otherwise there is insufficient evidence to recommend one insertion site over another

- Avoid the subclavian site in hemodialysis patients and patients with advanced kidney disease, to avoid subclavian vein stenosis

- Image guided insertion of CVC is recommended

- Prophylactic use of systemic antibiotics is not recommended before CVC insertion

- Promptly remove any CVC that is no longer essential

CVC care

- CVC bundled care including hand hygiene, maximal barrier precautions, chlorhexidine skin antisepsis during insertion and regular assessment of the CVC is recommended

Abbreviation: $\mathrm{HCT}=$ hematopoietic cell transplantation. Recommendations for prevention of CVC-related infections, adopted from evidence-based guidelines Healthcare Infection Control Practices Advisory Committee ${ }^{84}$ and the American Society of Clinical Oncology. ${ }^{93}$

Empiric antibiotics in febrile patients

After fever develops in HCT recipients, rapid administration of empiric antibiotics has been shown to reduce patient mortality. ${ }^{82,83}$ Choice of empirical antimicrobial therapy incorporates patient's clinical manifestation (severity and type of signs and symptoms associated with fever and clinical risk factors for infectious complications), disease severity, and risk factors. Specific knowledge of resistance patterns in the HCT population is crucial as HCT patients tend to harbor more resistant bacteria compared with the general hospital population. ${ }^{84}$

Stoma et al. $^{83}$ recently showed an increase in 30 day all-cause mortality in patients who received inadequate empirical antibiotics which were defined by: (a) resistance of the isolated microorganisms to the administered antibiotics; (b) empiric antibacterial therapy that was administered $>24 \mathrm{~h}$ after collection of blood cultures; or (c) a dosing regimen that conflicted with standard dosing recommendations. This finding underscores the importance of knowledge of the local spectrum of pathogens, which is imperative for selecting the appropriate empiric antibacterial regimen.

\section{BLOODSTREAM INFECTION PREVENTION}

Catheter care bundles

Catheter care bundles consist of a standard combination of evidence-based interventions that have been shown to be effective in preventing CLABSIs and improving patient outcomes. ${ }^{81,85}$ Germane bundle components include performance of hand hygiene, full-barrier precautions including use of sterile technique and chlorhexidine cleansing during insertion, and proper procedures for CVC access, manipulation and dressing changes. 
In 2011, the Healthcare Infection Control Practices Advisory Committee composed of members from professional organizations representing various major disciplines of healthcare created the 'Guidelines for the Prevention of Intravascular Cather-Related Infections'. ${ }^{81}$ These recommendations included focusing on education of healthcare providers who place and maintain CVCs, utilization of sterile techniques in CVC insertion and maintenance and implementation of standardized bundled strategies to prevent infections. ${ }^{81}$ In 2013, the American Society of Clinical Oncology created evidence-based guidelines for CVC care in patients with cancer, ${ }^{85}$ incorporating all relevant literature associated with CVC placement and care in patients with cancer. The summary of the recommendations from both initiatives are detailed in Table 3. Standardization of bundle elements coupled with systematic implementation and compliance has been shown to effectively and significantly reduce CLABSI rates across multiple studies involving pediatric oncology and HCT patients in the inpatient setting. ${ }^{86-90}$ Best practice bundle implementation with particular focus on maintenance strategies also reduces CLABSI rates in the ambulatory setting. ${ }^{86,91}$

As part of a multicenter quality improvement initiative, 32 pediatric hematology/oncology and HCT centers across the United States implemented a standardized CVC care bundle. Average compliance with the CVC care bundle across the institutions was more than $80 \%$ during the study period; and the collaboration demonstrated a $29 \%$ reduction in CLABSI rates from $2.85 \mathrm{CLABSI}$ to $2.04 \mathrm{CLABSI} / 1000 \mathrm{CVC}$ days (RR: $0.71,95 \% \mathrm{Cl}$ : $0.55-0.92) .{ }^{92}$ This multi-institutional collaborative improvement effort succeeded at reducing CLABSI rates through standardized CVC bundle care in immunocompromised patients. In a recent study from MSKCC, rates of hospital-acquired CLABSI in high-risk adult patients including HCT recipients decreased by $34 \%$ to 2.3/1000 days after implementing a disinfection cap and resulted in substantial cost savings. ${ }^{93}$

\section{Prophylactic antibiotics}

According to recent BMT guidelines, fluoroquinolone prophylaxis should be considered for HCT patients with anticipated neutropenic periods of $\geqslant 7$ days. ${ }^{94}$ Antibacterial prophylaxis is generally started at the time of hematopoietic cell infusion and continued until recovery from neutropenia or initiation of empirical antibacterial therapy for fever. ${ }^{94}$

Use of prophylactic antibiotics in neutropenic adult oncology patients has consistently shown efficacy in reducing the incidence of fever and microbiologically-documented bacterial infections, but has not improved OS. ${ }^{95,96}$ Furthermore, some reports addressing the utility of prophylactic antibiotics in HCT patients are contradictory. Liu et al. showed that levofloxacin prophylaxis did not affect time to BSI development, 6-month mortality and incidence of gram positive and gram negative isolates. ${ }^{97}$ In addition, prophylaxis may have increased MDR bacterial strains. ${ }^{97}$ Satlin et al. ${ }^{98}$ reported $27 \%$ absolute reduction in BSI and $31 \%$ absolute reduction in febrile neutropenia episodes within 30 days after HCT in patients receiving levofloxacin prophylaxis. However, they also demonstrated a non-significant increase in Clostridium difficile and fluoroquinolone-resistant Enterobacteriaceae infections. ${ }^{98}$ Finally, levofloxacin prophylaxis was not associated with decreased BSI rates complicated by severe sepsis or ICU admission. ${ }^{98}$

It is important to note that any benefit for fluoroquinolone prophylaxis could potentially be offset by increased rates of emerging resistant pathogens. ${ }^{99,100}$ The proportion of BSIs caused by fluoroquinolone-resistant bacteria has increased (Tables 1 and 2), likely secondary to the use of fluoroquinolone prophylaxis. Epidemiological data should be reviewed closely prior to implementing fluoroquinolone prophylaxis and if applied, centers should actively monitor for emergence of resistant organisms. ${ }^{94}$

\section{Prophylactic antibiotics after Day 100}

Antibiotic prophylaxis is recommended for preventing S. pneumoniae infections among allo-HCT recipients receiving immunosuppressive therapy directed against chronic GvHD. Antibiotic selection should be predicated on the local resistance patterns, but usually involves oral penicillin or first-generation cephalosporin use in penicillinallergic patients. $^{94}$

\section{Ig prophylaxis}

Routine prophylaxis with IV Ig is not recommended given no demonstrable benefit for reducing incidence in bacterial, fungal and viral infections. ${ }^{101}$ However, IVIG is typically used in adult and pediatric HCT patients with hypogammaglobinemia (serum IgG $<400 \mathrm{mg} / \mathrm{dL}$ ) and recurrent bacterial infections. ${ }^{101}$

\section{Vaccination}

Invasive Streptococcus pneumoniae is a significant complication following HCT and is associated with $20 \%$ mortality in transplant recipients. ${ }^{102}$ Vaccination is an important strategy to prevent S. pneumoniae infection after HCT. ${ }^{94}$ Pneumovax (PPSV23) is a polysaccharide vaccine representing 23 of the most prevalent serotypes of Pneumococcus. Prevnar (PCV13) is a 13-valent conjugate vaccine that is approved for all individuals over 6 weeks of age. ${ }^{103}$ Prevnar is more immunogenic than Pneumovax secondary to inducing more durable, T-cell dependent memory responses. ${ }^{104,105}$ Unless a patient is severely immunocompromised, Prevnar should be started at 6 months post HCT for a total of three doses, each administered two months apart. ${ }^{105,106}$ One dose of Pneumovax should be given 6 to 12 months after the last Prevnar dose. ${ }^{106,107}$ The recent 10-year decline in invasive pneumococcal disease among patients with hematologic malignancies in the US coincides with incorporation of Prevnar in universal childhood immunization. ${ }^{108}$

\section{Interventions to prevent bacteremia from oral bacteria}

Mucositis has a profound negative effect on nutritional status, oral intake of food and medications, and quality of life in HCT patients. ${ }^{109}$ Chemotherapy and irradiation not only damage the gastrointestinal tract, allowing bacterial constituents to enter the systemic circulation (that is, bacterial transmigration and subsequent bacteremia), but also activate aGvHD, an inflammatory cytokine-associated alloreactivity that causes further insult to gastrointestinal epithelium. ${ }^{110}$ Surprisingly, mucositis severity does not correlate with incidence of BSI. For example, prospective studies evaluating interventions that are effective in reducing mucositis like keratinocyte growth factor ${ }^{111}$ and cryotherapy ${ }^{112}$ have not shown a beneficial effect in reducing BSI rates.

Gingivitis is closely associated with dental plaque on the teeth and gingival tissues ${ }^{113}$ and is an important contributor to mucosal toxicity seen after HCT. ${ }^{114}$ One cubic millimeter $\left(\mathrm{mm}^{3}\right)$ of dental plaque contains about 100 million bacteria that serve as a persistent reservoir for potential bacteremia. ${ }^{115}$ Dental plaque is a well-documented cause of gingivitis ${ }^{116}$ and is significantly associated with bacteremia in healthy subjects ${ }^{117}$ and HCT patients. ${ }^{118}$ Interestingly, a meta-analysis confirms that plaque accumulation and gingival inflammation score significantly to increase BSI risk following tooth brushing in healthy subjects. ${ }^{119}$ However, how dental plaque contributes to mucositis in HCT patients remains unstudied.

Oral rinses have been used to enhance oral hygiene and to decrease oral mucositis in HCT patients. Bland rinses such as $0.9 \%$ saline or sodium bicarbonate/saline as well as analgesics, mucosal coating agents and topical anesthetic solutions like 
viscous lidocaine and diphenhydramine solutions have been studied. ${ }^{120,121}$ Chlorhexidine has also been widely used as a bacteriostatic/cidal agent to reduce bacterial colony-forming units (CFUs), but has not been shown to reduce BSI from oral flora. ${ }^{122,123}$ Furthermore, chlorhexidine has a bitter taste, and is unpalatable to patients, particularly children, reducing compliance.

A comprehensive dental evaluation and plan for oral care periand post-HCT are important in preventing odontogenic infection and mucositis throughout the HCT period. ${ }^{124}$ A definitive dental treatment plan that includes oral hygiene reduces the incidence and severity of mucositis and may prevent infections and decrease infection-related mortality. ${ }^{121,125-127}$ In a small prospective evaluation of periodontal disease in adult HCT recipients, periodontal status correlated with frequency of bacteremia, particularly due to viridans streptococci and Staphylococcus epidermidis. ${ }^{118}$ Recent oral care guidelines recommend brushing with an ultra-soft toothbrush two to three times daily and using non-flavored chlorhexidine gluconate $0.12-0.2 \%$ solution as an oral antiseptic twice daily when oral hygiene is suboptimal after HCT. ${ }^{128}$ Adjunctive therapies with some supporting evidence include the use of KGF, patient-controlled analgesia and low-level laser therapy for mucositis prevention in patients receiving high-dose chemotherapy or irradiation for HCT. ${ }^{127}$

\section{Skin decontamination}

Use of chlorhexidine washes in the intensive care unit setting and in patients undergoing cardiac surgery prevents CLABSI and surgical site infections, respectively. ${ }^{129,130} \mathrm{~A}$ multicenter, clusterrandomized, non-blinded crossover trial that included patients in HCT units found that daily bathing with chlorhexidineimpregnated washcloths significantly reduced acquisition of MDR organisms and development of hospital-acquired CLABSIs, particularly those caused by gram positive bacteria and fungi. ${ }^{131}$ Current clinical trials are evaluating whether receipt of daily chlorohexidine topical skin wipes for 90 days decreases CLABSI rates in children after allo-HCT.

\section{Maintaining the microbiome}

The human body is host to microbial communities (microbiome) ${ }^{132}$ that influence human physiology through processes related to development, nutrition, immunity and resistance to pathogens. ${ }^{133}$ Taxonomic profiling the Gl microbiome reveals large diversity in obligate anaerobic bacteria in healthy individuals. ${ }^{134}$ The host's immune system keeps the gut microbiota stable and prevents overgrowth of pathogenic species by producing antimicrobial peptides. The gut microbiota also influences immune responses by triggering differentiation of $T_{H} 17$, regulatory and memory $T$ cells and maturation in NKT cells. ${ }^{135}$ Disturbances in the microbiome (dysbiosis) are linked to intestinal inflammation and increased prevalence of potentially harmful facultative anaerobic bacteria. ${ }^{136}$
During $\mathrm{HCT}$, patients experience dramatic alterations in the intestinal microbiota with marked decreases in overall bacterial diversity, increasing risk for aGvHD and BSI. ${ }^{137}$ In many instances, a single bacterial taxon can predominate and replace a previously rich and diverse milieu of organisms. ${ }^{137}$ Low microbiome diversity and dysbiosis have independently been associated with BSI and transplant-related mortality. ${ }^{138}$ That is, conditioning regimen insult to the Gl tract in combination with antibiotic use prior to neutrophil engraftment decreases microbiome diversity and increases subsequent risk for bacteremia from MBI-LCBI organisms. ${ }^{77,137,139}$ Loss of microbiome diversity leads to domination of $\mathrm{MBI}-\mathrm{LCBI}$ pathogens within the GI tract and subsequent systemic infection with the corresponding blood pathogen. ${ }^{137}$ This observation corroborates that neutropenia-associated BSIs arise largely from a gastrointestinal source via a transformation in the gut microbiome resulting in loss of colonization resistance and subsequent overgrowth by a single bacterial species that then translocates through damaged epithelium into the bloodstream.

Several lines of evidence confirm that antibiotic administration can result in gut microbiota dysbiosis or aberrant alteration in the GI commensal bacteria. ${ }^{132,140}$ Broad-spectrum antibiotics can influence bacterial species in the gut community, causing rapid and significant reductions in taxonomic richness, diversity and evenness. ${ }^{140}$ In addition, antibiotics alter the composition of taxa, affecting gene expression and protein activity as well as overall metabolism of the gut. ${ }^{141}$ In a retrospective analysis of 857 allo-HCT recipients, Shono et al. found that empiric fever and neutropenia ( $F \& N)$ therapy using imipenem-cilastatin and piperacillin-tazobactam antibiotics was associated with increased GvHD-related mortality at 5 years $(21.5 \%$ for imipenem-cilastatin-treated patients vs $13.1 \%$ for untreated patients, $P=0.025$; $19.8 \%$ for piperacillin-tazobactam-treated patients vs $11.9 \%$ for untreated patients, $P=0.007) .{ }^{31}$ However, two other antibiotics also used to treat F\&N, aztreonam and cefepime, were not associated with GvHD-related mortality $(P=0.78$ and $P=0.98$, respectively). Analysis of stool specimens from allo-HCT recipients showed that piperacillin-tazobactam administration was associated with perturbations in gut microbial composition. ${ }^{31}$ In addition, when compared to a contemporaneous hospital cohort, HCT recipients developed more resistance against commonly isolated bacterial organisms. These findings have important clinical implications regarding use and selection of both prophylactic and empiric antibiotic regimens.

Emerging data parsing $\mathrm{MBI}-\mathrm{LCBI}$ from CLABSI highlight that almost half of BSI in pediatric HCT are indeed MBI-LCBIs and are associated with a significant increased risk of non-relapse mortality. ${ }^{5}$ This distinction may contribute to further reduction in true CLABSI rates in this population ${ }^{15,142-144}$ and may provide an opportunity for identification of risk factors specific to MBI-LCBI in HCT patients, enabling more targeted prevention strategies, distinct from current CLABSI prevention strategies.

Table 4. Outcomes in pediatric HCT patients developing BSI

\begin{tabular}{|c|c|c|c|}
\hline & $M B I-L C B I(\mathrm{~N}=80)$ & CLABSI $(\mathrm{n}=68)$ & Secondary BSI $(\mathrm{n}=22)$ \\
\hline Central line removed Within 7 days & $31(39 \%)$ & $30(44 \%)$ & $10(45 \%)$ \\
\hline Transfer to ICU within $48 \mathrm{~h}$ of $\mathrm{BSI}$ & 17 of $73(23 \%)$ & 14 of $59(24 \%)$ & 2 of $13(15 \%)$ \\
\hline Patients in ICU at time of infection & 7 & 9 & 9 \\
\hline Median ICU days in patients transferred from floor (IQR) & $6(3-10)$ & $5(3-15)$ & $32(18-46)$ \\
\hline
\end{tabular}




\section{OUTCOMES IN TRANSPLANT PATIENTS WHO DEVELOP BLOODSTREAM INFECTIONS}

BSI alone is a significant independent predictor of TRM. Poutsiaka et al. described increased TRM (HR 1.79, 95\% Cl 1.18-2.73, $P=0.007)$ after adjusting aGvHD and allo-HCT with both predicting death three months after HCT. In addition, they found that bacteremia with GN rods and VRE were also significantly associated with increased morality. ${ }^{4}$ Liu et al. ${ }^{97}$ confirmed the negative impact of BSI on 6-month survival post HCT and demonstrated that patients who developed BSI had increased length of hospital stay. In a retrospective analysis, Dandoy et al. ${ }^{5}$ studied outcomes from 170 BSIs diagnosed in 100 (27\%) of 374 pediatric patients undergoing HCT. They showed that BSIs were associated with increased morbidity and mortality, leading to significant resource utilization as detailed in Table 4. Specifically, 1-year non-relapse mortality was significantly increased in patients with one $(20 / 58,34 \%)$ and more than one $(17 / 30,56 \%) B S I$ in the first year post-HCT compared with those who did not develop BSI $(27 / 194,14 \% ; P=<0.0001)$. In addition, increased risk of one-year non-relapse mortality was noted in patients with at least one MBI-LCBI (OR 1.94, $P=0.018)$ and at least one secondary $\mathrm{BSI}$ (OR 2.87, $P=0.0023$ ), but not in patients with CLABSI (OR 1.17, $P=0.68) .{ }^{5}$ Levinson et al. ${ }^{29}$ showed that in addition to increased non-relapse mortality, patients who developed early BSI during the conditioning regimen and within 10 days after HCT (and prior to engraftment) had a twofold increase risk in developing aGvHD. Taken together, these results demonstrate that $\mathrm{BSI}$, in general, and $\mathrm{MBI}-\mathrm{LCBI}$, in particular, not only cause significant harm to HCT patients, increasing their risk for adverse outcomes as well as aGvHD, but also prolong hospitalization and potentially increase significant hospital resource utilization.

\section{HEALTHCARE COSTS ASSOCIATED WITH BLOODSTREAM INFECTIONS}

A published meta-analysis of healthcare associated infections (HAls) revealed that CLABSIs are associated with the highest cost of any $\mathrm{HAl}$, averaging $\$ 45814$ per event. ${ }^{145} \mathrm{~A}$ recent evaluation in pediatric HCT and oncology patients with ambulatory BSIs demonstrated a $\$ 40852$ median hospital charge with room, pharmacy and procedure charges accounting for more than $70 \%$ of total charges. ${ }^{146}$ Finally, Wilson et al. ${ }^{6}$ utilized propensity scoring with matched cases while controlling for other covariates and defined the attributable cost of CLABSI to approximate $\$ 70000$ per $\mathrm{BSI}$ event in pediatric hematology oncology patients. In addition, patients with CLABSI had length of stay that were 21.2 days longer than those without CLABSI $(P<0.0001){ }^{6}$

\section{SUMMARY}

BSIs are a leading cause of transplant-related morbidity and mortality in allo-HCT recipients. In particular, emergence of antimicrobial-resistant bacterial pathogens is daunting, as antimicrobial agents with efficacy to eradicate such infections are limited. Therefore, judicious use of antimicrobial agents and optimal prevention strategies are needed to reduce CLABSI-related infection burden in allo-HCT patients. Additional research efforts should focus on defining the etiology and resistance patterns of bacterial pathogens responsible for BSI given their rising incidence and detrimental impact on the allo-HCT patient outcomes.

\section{CONFLICT OF INTEREST}

JJA: Advisory Board, Shire Pharmaceuticals (2016). The remaining authors declare no conflict of interest.

\section{ACKNOWLEDGEMENTS}

GAP work was supported by NCI National Institutes of Health Cancer Center Support Grant P30 CA008748.

\section{AUTHOR CONTRIBUTIONS}

CED: Primary manuscript writing and review; MIA and GAP: Manuscript writing and review; JJA: Manuscript writing, review and overall concept design.

\section{REFERENCES}

1 Barriga F, Ramírez P, Wietstruck A, Rojas N. Hematopoietic stem cell transplantation: clinical use and perspectives. Biol Res 2012; 45: 307-316.

2 Copelan EA. Hematopoietic stem-cell transplantation. N Engl J Med 2006; 354: 1813-1826.

3 Remberger M, Ackefors M, Berglund S, Blennow O, Dahllöf G, Dlugosz A et al. Improved survival after allogeneic hematopoietic stem cell transplantation in recent years. A single-center study. Biol Blood Marrow Transplant 2011; 17: 1688-1697.

4 Poutsiaka DD, Price LL, Ucuzian A, Chan GW, Miller KB, Snydman DR. Blood stream infection after hematopoietic stem cell transplantation is associated with increased mortality. Bone Marrow Transplant 2007; 40: 63-70.

5 Dandoy CE, Haslam D, Lane A, Jodele S, Demmel K, El-Bietar J et al. Healthcare burden, risk factors, and outcomes of mucosal barrier injury laboratoryconfirmed bloodstream infections after stem cell transplantation. Biol Blood Marrow Transplant 2016; 22: 1671-1677.

6 Wilson MZ, Rafferty C, Deeter D, Comito MA, Hollenbeak CS. Attributable costs of central line-associated bloodstream infections in a pediatric hematology/ oncology population. Am J Infect Control 2014; 42: 1157-1160.

7 Cecinati V, Brescia L, Tagliaferri L, Giordano P, Esposito S. Catheter-related infections in pediatric patients with cancer. Eur J Clin Microbiol Infect Dis 2012; 31: 2869-2877.

8 Dudeck MA, Edwards JR, Allen-Bridson K, Gross C, Malpiedi PJ, Peterson KD et al. National healthcare safety network report, data summary for 2013, Deviceassociated module. Am J Infect Control 2015; 43: 206-221.

9 See I, Iwamoto M, Allen-Bridson K, Horan T, Magill SS, Thompson ND. Mucosal barrier injury laboratory-confirmed bloodstream infection: results from a field test of a new National Healthcare Safety Network definition. Infect Control Hosp Epidemiol 2013; 34: 769-776.

10 Freeman JT, Elinder-Camburn A, McClymont C, Anderson DJ, Bilkey M, Williamson DA et al. Central line-associated bloodstream infections in adult hematology patients with febrile neutropenia: an evaluation of surveillance definitions using differential time to blood culture positivity. Infect Control Hosp Epidemiol 2013; 34: 89-92.

11 Jodele S, Fukuda T, Mizuno K, Vinks AA, Laskin BL, Goebel J et al. Variable Eculizumab clearance requires pharmacodynamic monitoring to optimize therapy for thrombotic microangiopathy after hematopoietic stem cell transplantation. Biol Blood Marrow Transplant 2016; 22: 307-315.

12 Bundy DG, Gaur AH, Billett AL, He B, Colantuoni EA, Miller MR et al. Preventing CLABSIs among pediatric hematology/oncology inpatients: national collaborative results. Pediatrics 2014; 134: e1678-e1685.

13 Pronovost $\mathrm{P}$, Needham D, Berenholtz S, Sinopoli D, Chu H, Cosgrove S et al. An intervention to decrease catheter-related bloodstream infections in the ICU. N Engl J Med 2006; 355: 2725-2732.

14 Miller MR, Griswold M, Harris JM, Yenokyan G, Huskins WC, Moss M et al. Decreasing PICU catheter-associated bloodstream infections: NACHRI's quality transformation efforts. Pediatrics 2010; 125: 206-213.

15 Metzger KE, Rucker Y, Callaghan M, Churchill M, Jovanovic BD, Zembower TR et al. The burden of mucosal barrier injury laboratory-confirmed bloodstream infection among hematology, oncology, and stem cell transplant patients. Infect Control Hosp Epidemiol 2015; 36: 119-124.

16 Mermel LA, Allon M, Bouza E, Craven DE, Flynn P, O'Grady NP et al. Clinical practice guidelines for the diagnosis and management of intravascular catheter-related infection: 2009 Update by the Infectious Diseases Society of America. Clin Infect Dis 2009; 49: 1-45.

17 Gaur AH, Flynn PM, Giannini MA, Shenep JL, Hayden RT. Difference in time to detection: a simple method to differentiate catheter-related from noncatheter-related bloodstream infection in immunocompromised pediatric patients. Clin Infect Dis 2003; 37: 469-475.

18 Gaur AH, Flynn PM, Heine DJ, Giannini MA, Shenep JL, Hayden RT. Diagnosis of catheter-related bloodstream infections among pediatric oncology patients lacking a peripheral culture, using differential time to detection. Pediatr Infect Dis J 2005; 24: 445-449. 
19 Mikulska M, Del Bono V, Raiola AM, Bruno B, Gualandi F, Occhini D et al. Blood stream infections in allogeneic hematopoietic stem cell transplant recipients: reemergence of Gram-negative rods and increasing antibiotic resistance. Biol Blood Marrow Transplant 2009; 15: 47-53.

20 Kikuchi M, Akahoshi Y, Nakano H, Ugai T, Wada H, Yamasaki R et al. Risk factors for pre- and post-engraftment bloodstream infections after allogeneic hematopoietic stem cell transplantation. Transpl Infect Dis 2015; 17: 56-65.

21 Gudiol C, Garcia-Vidal C, Arnan M, Sánchez-Ortega I, Patiño B, Duarte R et al. Etiology, clinical features and outcomes of pre-engraftment and post-engraftment bloodstream infection in hematopoietic SCT recipients. Bone Marrow Transplant 2014; 49: 824-830.

22 Mitchell AE, Derrington P, Turner P, Hunt LP, Oakhill A, Marks DI. Gram-negative bacteraemia (GNB) after 428 unrelated donor bone marrow transplants (UD-BMT): risk factors, prophylaxis, therapy and outcome. Bone Marrow Transplant 2004; 33: 303-310.

23 Ballen K, Woo Ahn K, Chen M, Abdel-Azim H, Ahmed I, Aljurf M et al. Infection rates among acute leukemia patients receiving alternative donor hematopoietic cell transplantation. Biol Blood Marrow Transplant 2016; 22: 1636-1645.

24 Sanz J, Cano I, González-Barberá EM, Arango M, Reyes J, Montesinos P et al. Bloodstream infections in adult patients undergoing cord blood transplantation from unrelated donors after myeloablative conditioning regimen. Biol Blood Marrow Transplant 2015; 21: 755-760.

25 Young JA, Logan BR, Wu J, Wingard JR, Weisdorf DJ, Mudrick C et al. Infections after transplantation of bone marrow or peripheral blood stem cells from unrelated donors. Biol Blood Marrow Transplant 2016; 22: 359-370.

26 Crocchiolo R, Bramanti S, Vai A, Sarina B, Mineri R, Casari E et al. Infections after T-replete haploidentical transplantation and high-dose cyclophosphamide as graft-versus-host disease prophylaxis. Transpl Infect Dis 2015; 17: 242-249.

27 Kim SH, Kee SY, Lee DG, Choi SM, Park SH, Kwon JC et al. Infectious complications following allogeneic stem cell transplantation: reduced-intensity vs. myeloablative conditioning regimens. Transpl Infect Dis 2013; 15: 49-59.

28 Blennow O, Ljungman P, Sparrelid E, Mattsson J, Remberger M. Incidence, risk factors, and outcome of bloodstream infections during the pre-engraftment phase in 521 allogeneic hematopoietic stem cell transplantations. Transpl Infect Dis 2014; 16: 106-114.

29 Levinson A, Pinkney K, Jin Z, Bhatia M, Kung AL, Foca MD et al. Acute gastrointestinal graft-vs-host disease is associated with increased enteric bacterial bloodstream infection density in pediatric allogeneic hematopoietic cell transplant recipients. Clin Infect Dis 2015; 61: 350-357.

30 Poutsiaka DD, Munson D, Price LL, Chan GW, Snydman DR. Blood stream infection (BSI) and acute GVHD after hematopoietic SCT (HSCT) are associated. Bone Marrow Transplant 2011; 46: 300-307.

31 Shono Y, Docampo MD, Peled JU, Perobelli SM, Velardi E, Tsai JJ et al. Increased GVHD-related mortality with broad-spectrum antibiotic use after allogeneic hematopoietic stem cell transplantation in human patients and mice. Sci TransI Med 2016; 8: 339ra71.

32 Eriguchi Y, Nakamura K, Hashimoto D, Shimoda S, Shimono N, Akashi K et al. Decreased secretion of Paneth cell a-defensins in graft-versus-host disease. Transpl Infect Dis 2015; 17: 702-706.

33 Eriguchi Y, Takashima S, Oka H, Shimoji S, Nakamura K, Uryu H et al. Graft-versushost disease disrupts intestinal microbial ecology by inhibiting Paneth cell production of a-defensins. Blood 2012; 120: 223-231.

34 Jodele S, Davies SM, Lane A, Khoury J, Dandoy C, Goebel J et al. Diagnostic and risk criteria for HSCT-associated thrombotic microangiopathy: a study in children and young adults. Blood 2014; 124: 645-653.

35 Sarashina T, Yoshida M, Iguchi A, Okubo H, Toriumi N, Suzuki D et al. Risk factor analysis of bloodstream infection in pediatric patients after hematopoietic stem cell transplantation. J Pediatr Hematol Oncol 2013; 35: 76-80.

36 Frère $P$, Hermanne JP, Debouge $M H$, de Mol $P$, Fillet $G$, Beguin $Y$. Bacteremia after hematopoietic stem cell transplantation: incidence and predictive value of surveillance cultures. Bone Marrow Transplant 2004; 33: 745-749.

37 Collin BA, Leather HL, Wingard JR, Ramphal R. Evolution, incidence, and susceptibility of bacterial bloodstream isolates from 519 bone marrow transplant patients. Clin Infect Dis 2001; 33: 947-953.

38 Mikulska M, Viscoli C, Orasch C, Livermore DM, Averbuch D, Cordonnier C et al. Aetiology and resistance in bacteraemias among adult and paediatric haematology and cancer patients. J Infect. 2014; 68: 321-331.

39 Vydra J, Shanley RM, George I, Ustun C, Smith AR, Weisdorf DJ et al. Enterococcal bacteremia is associated with increased risk of mortality in recipients of allogeneic hematopoietic stem cell transplantation. Clin Infect Dis. 2012; 55: 764-770.

40 Adams DJ, Eberly MD, Goudie A, Nylund CM. Rising Vancomycin-Resistant Enterococcus Infections in Hospitalized Children in the United States. Hosp Pediatr 2016; 6: 404-411.
41 Hidron Al, Edwards JR, Patel J, Horan TC, Sievert DM, Pollock DA et al. NHSN annual update: antimicrobial-resistant pathogens associated with healthcareassociated infections: annual summary of data reported to the National Healthcare Safety Network at the Centers for Disease Control and Prevention, 2006-2007. Infect Control Hosp Epidemiol 2008; 29: 996-1011.

42 Arias CA, Murray BE. The rise of the Enterococcus: beyond vancomycin resistance. Nat Rev Microbiol 2012; 10: 266-278.

43 Noskin GA, Stosor V, Cooper I, Peterson LR. Recovery of vancomycin-resistant enterococci on fingertips and environmental surfaces. Infect Control Hosp Epidemiol 1995; 16: 577-581.

44 Ray AJ, Hoyen CK, Taub TF, Eckstein EC, Donskey CJ. Nosocomial transmission of vancomycin-resistant enterococci from surfaces. JAMA 2002; 287: 1400-1401.

45 Kamboj M, Blair R, Bell N, Sun J, Eagan J, Sepkowitz K. What is the source of bloodstream infection due to vancomycin-resistant enterococci in persons with mucosal barrier injury? Infect Control Hosp Epidemiol 2014; 35: 99-101.

46 Ubeda C, Taur Y, Jenq RR, Equinda MJ, Son T, Samstein $M$ et al. Vancomycin-resistant Enterococcus domination of intestinal microbiota is enabled by antibiotic treatment in mice and precedes bloodstream invasion in humans. J Clin Invest 2010; 120: 4332-4341.

47 Archer NK, Mazaitis MJ, Costerton JW, Leid JG, Powers ME, Shirtliff ME. Staphylococcus aureus biofilms: properties, regulation, and roles in human disease. Virulence 2011; 2: 445-459.

48 Foster TJ, Höök M. Surface protein adhesins of Staphylococcus aureus. Trends Microbiol 1998; 6: 484-488.

49 Fridkin SK, Hageman JC, Morrison M, Sanza LT, Como-Sabetti K, Jernigan JA et al. Methicillin-resistant Staphylococcus aureus disease in three communities. N Engl J Med 2005; 352: 1436-1444.

50 Shaw BE, Boswell T, Byrne JL, Yates C, Russell NH. Clinical impact of MRSA in a stem cell transplant unit: analysis before, during and after an MRSA outbreak. Bone Marrow Transplant 2007; 39: 623-629.

51 Liss BJ, Vehreschild JJ, Cornely OA, Hallek M, Fätkenheuer G, Wisplinghoff H et al. Intestinal colonisation and blood stream infections due to vancomycin-resistant enterococci (VRE) and extended-spectrum beta-lactamase-producing Enterobacteriaceae (ESBLE) in patients with haematological and oncological malignancies. Infection 2012; 40: 613-619.

52 Nesher L, Rolston KV, Shah DP, Tarrand JT, Mulanovich V, Ariza-Heredia EJ et al. Fecal colonization and infection with Pseudomonas aeruginosa in recipients of allogeneic hematopoietic stem cell transplantation. Transpl Infect Dis 2015; 17: 33-38.

53 Satlin MJ, Cohen N, Ma KC, Gedrimaite Z, Soave R, Askin G et al. Bacteremia due to carbapenem-resistant Enterobacteriaceae in neutropenic patients with hematologic malignancies. J Infect 2016; 73: 336-345.

54 Aitken SL, Tarrand JJ, Deshpande LM, Tverdek FP, Jones AL, Shelburne SA et al. High Rates of Nonsusceptibility to Ceftazidime-avibactam and Identification of New Delhi Metallo- $\beta$-lactamase Production in Enterobacteriaceae Bloodstream Infections at a Major Cancer Center. Clin Infect Dis 2016; 63: 954-958.

55 Girmenia C, Rossolini GM, Piciocchi A, Bertaina A, Pisapia G, Pastore D et al. Infections by carbapenem-resistant Klebsiella pneumoniae in SCT recipients: a nationwide retrospective survey from Italy. Bone Marrow Transplant 2015; 50: 282-288.

56 Banerjee R, Teng CB, Cunningham SA, Ihde SM, Steckelberg JM, Moriarty JP et al. Randomized trial of rapid multiplex polymerase chain reaction-based blood culture identification and susceptibility testing. Clin Infect Dis 2015; 61: 1071-1080.

57 Idelevich EA, Silling G, Niederbracht Y, Penner H, Sauerland MC, Tafelski S et al. Impact of multiplex PCR on antimicrobial treatment in febrile neutropenia: a randomized controlled study. Med Microbiol Immunol 2015; 204: 585-592.

58 Nesher L, Chemaly RF, Shah DP, Mulanovich VE, Hosing C, Rolston KV. Utility of routine surveillance blood cultures in asymptomatic allogeneic hematopoietic stem cell transplant recipients with indwelling central venous catheters at a comprehensive cancer center. Am J Infect Control 2014; 42: 1084-1088.

59 Colombier MA, Lafaurie M, de Fontbrune FS, Resche-Rigon M, Donay JL, Pons JL et al. Usefulness of daily surveillance blood cultures in allogeneic hematopoietic stem cell transplant recipients on steroids: a 1-year prospective study. Transpl Infect Dis 2016; 18: 504-511.

60 Rigby H, Fernandez CV, Langley J, Mailman T, Crooks B, Higgins A. Routine surveillance for bloodstream infections in a pediatric hematopoietic stem cell transplant cohort: Do patients benefit? Can J Infect Dis Med Microbiol 2007; 18: 253-256.

61 Kanathezhath B, Shah A, Secola R, Hudes M, Feusner JH. The utility of routine surveillance blood cultures in asymptomatic hematopoietic stem cell transplant patients. J Pediatr Hematol Oncol 2010; 32: 327-331. 
62 Nijssen S, Fluit A, van de Vijver D, Top J, Willems R, Bonten MJ. Effects of reducing beta-lactam antibiotic pressure on intestinal colonization of antibiotic-resistant gram-negative bacteria. Intensive Care Med 2010; 36: 512-519.

63 Alexander S, Nieder M, Zerr DM, Fisher BT, Dvorak CC, Sung L. Prevention of bacterial infection in pediatric oncology: what do we know, what can we learn? Pediatr Blood Cancer 2012; 59: 16-20.

64 Siddiqui AH, Harris AD, Hebden J, Wilson PD, Morris JG, Roghmann MC. The effect of active surveillance for vancomycin-resistant enterococci in high-risk units on vancomycin-resistant enterococci incidence hospital-wide. Am J Infect Control 2002; 30: 40-43.

65 Miles-Jay A, Podczervinski S, Stednick ZJ, Pergam SA. Evaluation of routine pretransplantation screening for methicillin-resistant Staphylococcus aureus in hematopoietic cell transplant recipients. Am J Infect Control 2015; 43: 89-91.

66 Price JR, Golubchik T, Cole K, Wilson DJ, Crook DW, Thwaites GE et al. Wholegenome sequencing shows that patient-to-patient transmission rarely accounts for acquisition of Staphylococcus aureus in an intensive care unit. Clin Infect Dis 2014; 58: 609-618.

67 Kamboj M, Chung D, Seo SK, Pamer EG, Sepkowitz KA, Jakubowski AA et al. The changing epidemiology of vancomycin-resistant Enterococcus (VRE) bacteremia in allogeneic hematopoietic stem cell transplant (HSCT) recipients. Biol Blood Marrow Transplant 2010; 16: 1576-1581.

68 Girmenia C, Viscoli C, Piciocchi A, Cudillo L, Botti S, Errico A et al. Management of carbapenem resistant Klebsiella pneumoniae infections in stem cell transplant recipients: an Italian multidisciplinary consensus statement. Haematologica 2015; 100: e373-e376.

69 Lisboa LF, Miranda BG, Vieira MB, Dulley FL, Fonseca GG, Guimarães T et al. Empiric use of linezolid in febrile hematology and hematopoietic stem cell transplantation patients colonized with vancomycin-resistant Enterococcus spp. Int J Infect Dis 2015; 33: 171-176.

70 Kamboj M, Cohen N, Gilhuley K, Babady NE, Seo SK, Sepkowitz KA. Emergence of daptomycin-resistant VRE: experience of a single institution. Infect Control Hosp Epidemiol 2011; 32: 391-394.

71 Shukla BS, Shelburne S, Reyes K, Kamboj M, Lewis JD, Rincon SL et al. Influence of minimum inhibitory concentration in clinical outcomes of Enterococcus faecium bacteremia treated with daptomycin: is it time to change the breakpoint? Clin Infect Dis 2016; 62: 1514-1520.

72 Chuang YC, Lin HY, Chen PY, Lin CY, Wang JT, Chang SC. Daptomycin versus linezolid for the treatment of vancomycin-resistant enterococcal bacteremia: implications of daptomycin dose. Clin Microbiol Infect 2016; 22: 890e1-890e7.

73 McKinnell JA, Arias CA. Editorial Commentary: Linezolid vs daptomycin for vancomycin-resistant Enterococci: the evidence gap between trials and clinical experience. Clin Infect Dis 2015; 61: 879-882.

74 Sievert DM, Ricks P, Edwards JR, Schneider A, Patel J, Srinivasan A et al. Antimicrobial-resistant pathogens associated with healthcare-associated infections: summary of data reported to the National Healthcare Safety Network at the Centers for Disease Control and Prevention, 2009-2010. Infect Control Hosp Epidemiol 2013; 34: 1-14.

75 Satlin MJ, Jenkins SG, Walsh TJ. The global challenge of carbapenem-resistant Enterobacteriaceae in transplant recipients and patients with hematologic malignancies. Clin Infect Dis. 2014; 58: 1274-1283.

76 van Duin D, Bonomo RA. Ceftazidime/Avibactam and Ceftolozane/Tazobactam: second-generation $\beta$-lactam/ $\beta$-lactamase inhibitor combinations. Clin Infect Dis 2016; 63: 234-241.

77 Holler E, Butzhammer P, Schmid K, Hundsrucker C, Koestler J, Peter K et al. Metagenomic analysis of the stool microbiome in patients receiving allogeneic stem cell transplantation: loss of diversity is associated with use of systemic antibiotics and more pronounced in gastrointestinal graft-versus-host disease. Biol Blood Marrow Transplant 2014; 20: 640-645.

78 Safdar N, Maki DG. Use of vancomycin-containing lock or flush solutions for prevention of bloodstream infection associated with central venous access devices: a meta-analysis of prospective, randomized trials. Clin Infect Dis. 2006; 43: 474-484.

79 Worth LJ, Slavin MA, Heath S, Szer J, Grigg AP. Ethanol versus heparin locks for the prevention of central venous catheter-associated bloodstream infections: a randomized trial in adult haematology patients with Hickman devices. J Hosp Infect 2014; 88: 48-51.

80 Wolf J, Shenep JL, Clifford V, Curtis N, Flynn PM. Ethanol lock therapy in pediatric hematology and oncology. Pediatr Blood Cancer 2013; 60: 18-25.

81 O'Grady NP, Alexander M, Burns LA, Dellinger EP, Garland J, Heard SO et al. Guidelines for the prevention of intravascular catheter-related infections. Clin Infect Dis 2011; 52: e162-e193.

82 Freifeld AG, Bow EJ, Sepkowitz KA, Boeckh MJ, Ito Jl, Mullen CA et al. Clinical practice guideline for the use of antimicrobial agents in neutropenic patients with cancer: 2010 update by the Infectious Diseases Society of America. Clin Infect Dis 2011; 52: e56-e93.

83 Stoma I, Karpov I, Milanovich N, Uss A, Iskrov I. Risk factors for mortality in patients with bloodstream infections during the pre-engraftment period after hematopoietic stem cell transplantation. Blood Res 2016; 51: 102-106.

84 Bock AM, Cao Q, Ferrieri P, Young JA, Weisdorf DJ. Bacteremia in blood or marrow transplantation patients: clinical risk factors for infection and emerging antibiotic resistance. Biol Blood Marrow Transplant 2013; 19: 102-108.

85 Schiffer CA, Mangu PB, Wade JC, Camp-Sorrell D, Cope DG, El-Rayes BF et al. Central venous catheter care for the patient with cancer: American Society of Clinical Oncology clinical practice guideline. J Clin Oncol 2013; 31: 1357-1370.

86 Barrell C, Covington L, Bhatia M, Robison J, Patel S, Jacobson JS et al. Preventive strategies for central line-associated bloodstream infections in pediatric hematopoietic stem cell transplant recipients. Am J Infect Control 2012; 40: 434-439.

87 Rinke ML, Chen AR, Bundy DG, Colantuoni E, Fratino L, Drucis KM et al. Implementation of a central line maintenance care bundle in hospitalized pediatric oncology patients. Pediatrics 2012; 130: e996-e1004.

88 Chang AK, Foca MD, Jin Z, Vasudev R, Laird M, Schwartz S et al. Bacterial bloodstream infections in pediatric allogeneic hematopoietic stem cell recipients before and after implementation of a central line-associated bloodstream infection protocol: A single-center experience. Am J Infect Control 2016; 44: 1650-1655.

89 Choi SW, Chang L, Hanauer DA, Shaffer-Hartman J, Teitelbaum D, Lewis I et al. Rapid reduction of central line infections in hospitalized pediatric oncology patients through simple quality improvement methods. Pediatr Blood Cancer 2013; 60: 262-269.

90 Wilson MZ, Deeter D, Rafferty C, Comito MM, Hollenbeak CS. Reduction of central line-associated bloodstream infections in a pediatric hematology/ oncology population. Am J Med Qual 2014; 29: 484-490.

91 Rinke ML, Bundy DG, Chen AR, Milstone AM, Colantuoni E, Pehar M et al. Central line maintenance bundles and CLABSIs in ambulatory oncology patients. Pediatrics 2013; 132: e1403-e1412.

92 Bundy DG, Gaur AH, Billett AL, He B, Colantuoni EA, Miller MR. Preventing CLABSIs among pediatric hematology/oncology inpatients: national collaborative results. Pediatrics 2014; 134: e1678-e1685.

93 Kamboj M, Sheahan A, Sun J, Taur Y, Robilotti E, Babady E et al. Transmission of Clostridium difficile during hospitalization for allogeneic stem cell transplant. Infect Control Hosp Epidemiol. 2016; 37: 8-15.

94 Tomblyn M, Chiller T, Einsele H, Gress R, Sepkowitz K, Storek J et al. Guidelines for preventing infectious complications among hematopoietic cell transplant recipients: a global perspective. Preface. Bone Marrow Transplant 2009; 44: 453-455.

95 Bucaneve G, Micozzi A, Menichetti F, Martino P, Dionisi MS, Martinelli G et al. Levofloxacin to prevent bacterial infection in patients with cancer and neutropenia. N Engl J Med 2005; 353: 977-987.

96 Flowers CR, Seidenfeld J, Bow EJ, Karten C, Gleason C, Hawley DK et al. Antimicrobial prophylaxis and outpatient management of fever and neutropenia in adults treated for malignancy: American Society of Clinical Oncology clinical practice guideline. J Clin Oncol 2013; 31: 794-810.

97 Liu CY, Lai YC, Huang LJ, Yang YW, Chen TL, Hsiao LT et al. Impact of bloodstream infections on outcome and the influence of prophylactic oral antibiotic regimens in allogeneic hematopoietic SCT recipients. Bone Marrow Transplant 2011; 46: 1231-1239.

98 Satlin MJ, Vardhana S, Soave R, Shore TB, Mark TM, Jacobs SE et al. Impact of prophylactic Levofloxacin on rates of bloodstream infection and fever in neutropenic patients with multiple myeloma undergoing autologous hematopoietic stem cell transplantation. Biol Blood Marrow Transplant 2015; 21: 1808-1814.

99 Castagnola E, Boni L, Giacchino M, Cesaro S, De Sio L, Garaventa A et al. A multicenter, randomized, double blind placebo-controlled trial of amoxicillin/ clavulanate for the prophylaxis of fever and infection in neutropenic children with cancer. Pediatr Infect Dis J 2003; 22: 359-365.

100 Barone A. Antibacterial prophylaxis in neutropenic children with cancer. Pediatr Rep. 2011; 3: e3.

101 Raanani P, Gafter-Gvili A, Paul M, Ben-Bassat I, Leibovici L, Shpilberg O. Immunoglobulin prophylaxis in hematological malignancies and hematopoietic stem cell transplantation. Cochrane Database Syst Rev 2008; 4: CD006501.

102 Engelhard D, Cordonnier C, Shaw PJ, Parkalli T, Guenther C, Martino R et al. Early and late invasive pneumococcal infection following stem cell transplantation: a European Bone Marrow Transplantation survey. Br J Haematol 2002; 117: 444-450.

103 Nuorti JP, Whitney CG, Centers for Disease Control and Prevention (CDC). Prevention of pneumococcal disease among infants and children - use of 13 -valent pneumococcal conjugate vaccine and 23-valent pneumococcal polysaccharide vaccine - recommendations of the Advisory Committee on Immunization Practices (ACIP). MMWR Recomm Rep 2010; 59: 1-18. 
104 Cordonnier C, Labopin M, Robin C, Ribaud P, Cabanne L, Chadelat C et al. Longterm persistence of the immune response to antipneumococcal vaccines after allo-SCT: 10-year follow-up of the EBMT-IDWP01 trial. Bone Marrow Transplant 2015; 50: 978-983.

105 Cordonnier C, Ljungman P, Juergens C, Maertens J, Selleslag D, Sundaraiyer V et al. Immunogenicity, safety, and tolerability of 13-valent pneumococcal conjugate vaccine followed by 23 -valent pneumococcal polysaccharide vaccine in recipients of allogeneic hematopoietic stem cell transplant aged $\geq 2$ years: an open-label study. Clin Infect Dis 2015; 61: 313-323.

106 Carpenter PA, Englund JA. How I vaccinate blood and marrow transplant recipients. Blood 2016; 127: 2824-2832.

107 Cordonnier C, Labopin M, Chesnel V, Ribaud P, De La Camara R, Martino R et al. Randomized study of early versus late immunization with pneumococcal conjugate vaccine after allogeneic stem cell transplantation. Clin Infect Dis 2009; 48: 1392-1401.

108 Lee Y, Huang Y-T, Kim S, Kerpelev M, Gonzalez V, Papanicolaou G et al. Burden of pneumococcal disease in cancer patients: a 20 year single center study at Memorial Sloan-Kettering Cancer Center. Blood 2015; 126: 3303.

109 Al-Dasooqi N, Sonis ST, Bowen JM, Bateman E, Blijlevens N, Gibson RJ et al. Emerging evidence on the pathobiology of mucositis. Support Care Cancer 2013; 21: 3233-3241.

110 Chaudhry HM, Bruce AJ, Wolf RC, Litzow MR, Hogan WJ, Patnaik MS et al. The incidence and severity of oral mucositis among allogeneic hematopoietic stem cell transplantation patients: a systematic review. Biol Blood Marrow Transplant 2016; 22: 605-616.

111 Vadhan-Raj S, Trent J, Patel S, Zhou X, Johnson MM, Araujo D et al. Single-dose palifermin prevents severe oral mucositis during multicycle chemotherapy in patients with cancer: a randomized trial. Ann Intern Med 2010; 153: 358-367.

112 Svanberg A, Ohrn K, Birgegård G. Oral cryotherapy reduces mucositis and improves nutrition - a randomised controlled trial. J Clin Nurs 2010; 19: 2146-2151.

113 Pilot T, Barmes DE, Leclercq MH, McCombie BJ, Sardo Infirri J. Periodontal conditions in adolescents, 15-19 years of age: an overview of CPITN data in the WHO Global Oral Data Bank. Community Dent Oral Epidemiol 1987; 15: 336-338.

114 Ivanović M, Jovcić O, Mandić J, Bogetić D, Maddalone M. [Oral manifestations of acute leukaemia]. Srp Arh Celok Lek 2011; 139: 103-106.

115 Thoden van Velzen SK, Abraham-Inpijn L, Moorer WR. Plaque and systemic disease: a reappraisal of the focal infection concept. J Clin Periodontol 1984; 11: 209-220.

116 Mandel ID. Dental plaque: nature, formation and effects. J Periodontol 1966; 37: 537-567

117 Forner L, Larsen T, Kilian M, Holmstrup P. Incidence of bacteremia after chewing, tooth brushing and scaling in individuals with periodontal inflammation. J Clin Periodontol 2006; 33: 401-407.

118 Raber-Durlacher JE, Laheij AM, Epstein JB, Epstein M, Geerligs GM, Wolffe GN et al. Periodontal status and bacteremia with oral viridans streptococci and coagulase negative staphylococci in allogeneic hematopoietic stem cell transplantation recipients: a prospective observational study. Support Care Cancer 2013; 21: 1621-1627.

119 Tomás I, Diz P, Tobías A, Scully C, Donos N. Periodontal health status and bacteraemia from daily oral activities: systematic review/meta-analysis. J Clin Periodontol. 2012; 39: 213-228.

120 Peterson DE, Bensadoun RJ, Roila FGroup EGW. Management of oral and gastrointestinal mucositis: ESMO Clinical Practice Guidelines. Ann Oncol 2010; 21: v261-v265.

121 Best D, Osterkamp E, Demmel K, Kiniyalocts S, Mock S, Mulligan K et al. Increasing activities of daily living is as easy as 1-2-3. J Pediatr Oncol Nurs 2016; 33: 345-352.

122 Bortoluzzi MC, Santos FA. Amoxicillin and $0.12 \%$ chlorhexidine mouthwash may not be better than placebo for reducing bacteremia in third molar extractions. $J$ Evid Based Dent Pract 2014; 14: 34-35.

123 Smith K, Robertson DP, Lappin DF, Ramage G. Commercial mouthwashes are ineffective against oral MRSA biofilms. Oral Surg Oral Med Oral Pathol Oral Radiol 2013; 115: 624-629.

124 American Academy of Pediatric Dentistry. Guideline on dental management of pediatric patients receiving chemotherapy, hematopoietic cell transplantation, and/or radiation. Pediatr Dent 2013; 35: E185-E193.

125 Elad S, Thierer T, Bitan M, Shapira MY, Meyerowitz C. A decision analysis: the dental management of patients prior to hematology cytotoxic therapy or hematopoietic stem cell transplantation. Oral Oncol 2008; 44: 37-42.

126 Qutob AF, Allen G, Gue S, Revesz T, Logan RM, Keefe D. Implementation of a hospital oral care protocol and recording of oral mucositis in children receiving cancer treatment : a retrospective and a prospective study. Support Care Cancer 2013; 21: 1113-1120.
127 Lalla RV, Bowen J, Barasch A, Elting L, Epstein J, Keefe DM et al. MASCC/ISOO clinical practice guidelines for the management of mucositis secondary to cancer therapy. Cancer 2014; 120: 1453-1461.

128 Elad S, Raber-Durlacher JE, Brennan MT, Saunders DP, Mank AP, Zadik Y et al. Basic oral care for hematology-oncology patients and hematopoietic stem cell transplantation recipients: a position paper from the joint task force of the Multinational Association of Supportive Care in Cancer/International Society of Oral Oncology (MASCC/ISOO) and the European Society for Blood and Marrow Transplantation (EBMT). Support Care Cancer. 2015; 23: 223-236.

129 Milstone AM, Elward A, Song X, Zerr DM, Orscheln R, Speck K et al. Daily chlorhexidine bathing to reduce bacteraemia in critically ill children: a multicentre, cluster-randomised, crossover trial. Lancet 2013; 381: 1099-1106.

130 Chen W, Li S, Li L, Wu X, Zhang W. Effects of daily bathing with chlorhexidine and acquired infection of methicillin-resistant Staphylococcus aureus and vancomycin-resistant Enterococcus: a meta-analysis. J Thorac Dis 2013; 5: 518-524.

131 Climo MW, Yokoe DS, Warren DK, Perl TM, Bolon M, Herwaldt LA et al. Effect of daily chlorhexidine bathing on hospital-acquired infection. N Engl J Med 2013; 368: 533-542.

132 HMP Consortium. Structure, function and diversity of the healthy human microbiome. Nature 2012; 486: 207-214.

133 Li K, Bihan M, Yooseph S, Methé BA. Analyses of the microbial diversity across the human microbiome. PLOS ONE 2012; 7: e32118.

134 Eckburg PB, Bik EM, Bernstein CN, Purdom E, Dethlefsen L, Sargent M et al. Diversity of the human intestinal microbial flora. Science 2005; 308: 1635-1638.

135 Wang W, Xu S, Ren Z, Jiang J, Zheng S. Gut microbiota and allogeneic transplantation. J Transl Med 2015; 13: 275.

136 Winter SE, Lopez CA, Bäumler AJ. The dynamics of gut-associated microbial communities during inflammation. EMBO Rep 2013; 14: 319-327.

137 Taur Y, Xavier JB, Lipuma L, Ubeda C, Goldberg J, Gobourne A et al. Intestinal domination and the risk of bacteremia in patients undergoing allogeneic hematopoietic stem cell transplantation. Clin Infect Dis. 2012; 55: 905-914.

138 Taur Y, Jenq RR, Perales MA, Littmann ER, Morjaria S, Ling L et al. The effects of intestinal tract bacterial diversity on mortality following allogeneic hematopoietic stem cell transplantation. Blood 2014; 124: 1174-1182.

139 Galloway-Peña J, Smith D, Sahasrabhojane P, Ajami N, Wadsworth W, Daver N et al. The role of the gastrointestinal microbiome in infectious complications during induction chemotherapy for acute myeloid leukemia. Cancer 2016; 122: 2186-2196.

140 Dethlefsen L, Relman DA. Incomplete recovery and individualized responses of the human distal gut microbiota to repeated antibiotic perturbation. Proc Natl Acad Sci USA 2011; 108: 4554-4561.

141 Franzosa EA, Hsu T, Sirota-Madi A, Shafquat A, Abu-Ali G, Morgan XC et al. Sequencing and beyond: integrating molecular 'omics' for microbial community profiling. Nat Rev Microbiol 2015; 13: 360-372.

142 Epstein L, See I, Edwards JR, Magill SS, Thompson ND. Mucosal barrier injury laboratory-confirmed bloodstream infections (MBI-LCBI): descriptive analysis of data reported to National Healthcare Safety Network (NHSN), 2013. Infect Control Hosp Epidemiol 2016; 37: 2-7.

143 Torres D, Gonzalez ML, Loera A, Aguilera M, Relyea G, Aristizabal P et al. The Centers for Disease Control and Prevention definition of mucosal barrier injury-associated bloodstream infection improves accurate detection of preventable bacteremia rates at a pediatric cancer center in a low- to middleincome country. Am J Infect Control 2016; 44: 432-437.

144 Chaftari AM, Jordan M, Hachem R, Al Hamal Z, Jiang Y, Yousif A et al. A clinical practical approach to the surveillance definition of central line-associated bloodstream infection in cancer patients with mucosal barrier injury. Am J Infect Control 2016; 44: 931-934.

145 Zimlichman E, Henderson D, Tamir O, Franz C, Song P, Yamin CK et al. Health care-associated infections: a meta-analysis of costs and financial impact on the US health care system. JAMA Intern Med 2013; 173: 2039-2046.

146 Wong Quiles Cl, Gottsch S, Thakrar U, Fraile B, Billett AL. Health care institutional charges associated with ambulatory bloodstream infections in pediatric oncology and stem cell transplant patients. Pediatr Blood Cancer 2017; 64: 324-329.

147 Macesic N, Morrissey CO, Cheng AC, Spencer A, Peleg AY. Changing microbial epidemiology in hematopoietic stem cell transplant recipients: increasing resistance over a 9-year period. Transpl Infect Dis 2014; 16: 887-896.

148 Busca A, Cavecchia I, Locatelli F, D'Ardia S, De Rosa FG. Blood stream infections after allogeneic stem cell transplantation: a single-center experience with the use of levofloxacin prophylaxis. Transpl Infect Dis 2012; 14: 40-48.

149 Hong J, Moon SM, Ahn HK, Sym SJ, Park YS, Park J et al. Comparison of characteristics of bacterial bloodstream infection between adult patients with allogeneic and autologous hematopoietic stem cell transplantation. Biol Blood Marrow Transplant 2013; 19: 994-999. 
150 Tavadze M, Rybicki L, Mossad S, Avery R, Yurch M, Pohlman B et al. Risk factors for vancomycin-resistant enterococcus bacteremia and its influence on survival after allogeneic hematopoietic cell transplantation. Bone Marrow Transplant 2014; 49: 1310-1316.

151 Seo SK, Xiao K, Huang YT, Jongwutiwes U, Chung D, Maloy M et al. Impact of peri-transplant vancomycin and fluoroquinolone administration on rates of bacteremia in allogeneic hematopoietic stem cell transplant (HSCT) recipients: a 12-year single institution study. J Infect 2014; 69: 341-351.

152 Kobayashi R, Yabe H, Kikuchi A, Kudo K, Yoshida N, Watanabe K et al. Bloodstream infection after stem cell transplantation in children with idiopathic aplastic anemia. Biol Blood Marrow Transplant 2014; 20: 1145-1149.

153 Kelly M, Conway M, Wirth K, Potter-Bynoe G, Billett AL, Sendora TJ. Moving CLABSI prevention beyond the intensive care unit: risk factors in pediatric oncology patients. Infect Control Hosp Epidemiol 2011; 32: 1079-1085.
154 Wang L, Wang Y, Fan X, Tang W, Hu J. Prevalence of resistant gram-negative bacilli in bloodstream infection in febrile neutropenia patients undergoing hematopoietic stem cell transplantation: a single center retrospective cohort study. Medicine 2015; 94: e1931.

155 Lukenbill J, Rybicki L, Sekeres MA, Zaman MO, Copelan A, Haddad H et al. Defining incidence, risk factors, and impact on survival of central line-associated blood stream infections following hematopoietic cell transplantation in acute myeloid leukemia and myelodysplastic syndrome. Biol Blood Marrow Transplant 2013; 19: 720-724.

156 Gaur AH, Bundy DG, Gao C, Werner EJ, Billett AL, Hord JD et al. Surveillance of hospital-acquired central line-associated bloodstream infections in pediatric hematology-oncology patients: lessons learned, challenges ahead. Infect Control Hosp Epidemiol 2013; 34: 316-320.

157 Caselli D, Cesaro S, Fagioli F, Carraro F, Ziino O, Zanazzo G et al. Incidence of colonization and bloodstream infection with carbapenem-resistant Enterobacteriaceae in children receiving antineoplastic chemotherapy in Italy. Infect Dis 2016: 48: 152-155. 